\title{
Genetic diversity and population structure of Culex modestus across Europe: does recent appearance in the United Kingdom reveal a tendency for geographical spread?
}

\author{
Hernández-Triana, L. M.; Brugman, V. A.; Pramual, P.; Barrero, E.; Nikolova, N. I.; Ruiz-Arrondo, I.; \\ Kaiser, A.; Krüger, A.; Lumley, S.; Osório, H. C.
}

Total number of authors:

15

Published in:

Medical \& Veterinary Entomology

Link to article, DOI:

$10.1111 / \mathrm{mve} .12412$

Publication date:

2020

Document Version

Early version, also known as pre-print

Link back to DTU Orbit

Citation (APA):

Hernández-Triana, L. M., Brugman, V. A., Pramual, P., Barrero, E., Nikolova, N. I., Ruiz-Arrondo, I., Kaiser, A., Krüger, A., Lumley, S., Osório, H. C., Ignjatovi-upina, A., Petri, D., Laure Setier-Rio, M., Bødker, R., \& Johnson, N. (2020). Genetic diversity and population structure of Culex modestus across Europe: does recent appearance in the United Kingdom reveal a tendency for geographical spread? Medical \& Veterinary Entomology, 34(1), 8696. https://doi.org/10.1111/mve.12412

\section{General rights}

Copyright and moral rights for the publications made accessible in the public portal are retained by the authors and/or other copyright owners and it is a condition of accessing publications that users recognise and abide by the legal requirements associated with these rights.

- Users may download and print one copy of any publication from the public portal for the purpose of private study or research.

- You may not further distribute the material or use it for any profit-making activity or commercial gain

- You may freely distribute the URL identifying the publication in the public portal 
1 Genetic population structure and variation at phenology2 related loci in anadromous Arctic char (Salvelinus alpinus)

Rikke P.A. Madsen ${ }^{1}$, Magnus W. Jacobsen ${ }^{1 \$}$, Kathleen G. O'Malley ${ }^{2}$, Rasmus Nygaard $^{3}$, Kim Præbel ${ }^{4}$, Bjarni Jónsson ${ }^{5}$, Jose M. Pujolar ${ }^{1 €}$, Dylan J. Fraser ${ }^{6}$, Louis Bernatchez $^{7}$, Michael M. Hansen ${ }^{1 \S}$

${ }^{1}$ Department of Bioscience, Aarhus University, Ny Munkegade 114, DK-8000 Aarhus C, Denmark ${ }^{2}$ Coastal Oregon Marine Experiment Station, Hatfield Marine Science Center, Department of Fisheries and Wildlife, Oregon State University, 2030 SE Marine Science Drive, Newport, Oregon 97356 U.S.A.

${ }^{3}$ Greenland Institute of Natural Resources, Kivioq 2, P.O. Box 570, 3900 Nuuk, Greenland ${ }^{4}$ Norwegian College of Fishery Science, UiT the Arctic University of Norway, N-9032 Tromsø, Norway

${ }^{5}$ North West Iceland Nature Center, Adalgata 2, 550 Sudárkrókur, Iceland

${ }^{6}$ Department of Biology, Concordia University, Montreal, Québec, Canada

${ }^{7}$ IBIS (Institut de Biologie Intégrative et des Systèmes), Université Laval, Québec, Canada

\$Present address: National Institute of Aquatic Resources, Technical University of Denmark, Vejlsøvej 39, DK-8600 Silkeborg, Denmark

$€$ Present address: University of Copenhagen, National History Museum of Denmark, Universitetsparken 15, DK-2100 Copenhagen, Denmark

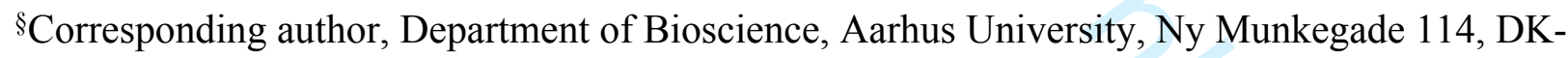
8000 Aarhus C, Denmark, e-mail mmh@bios.au.dk

Running Head: Phenology-related loci in Arctic char 


\section{Abstract}

The Arctic will be especially affected by climate change, resulting in altered seasonal timing. Anadromous Arctic char (Salvelinus alpinus) is strongly influenced by sea surface temperature (SST) delimiting time periods available for foraging in the sea. Recent studies of salmonid species have shown variation at phenology-related loci associated with timing of migration and spawning. We contrasted genetic population structure at 53 SNPs versus four phenology-related loci among 15 anadromous Arctic char populations from Western Greenland and three outgroup populations. Among anadromous populations, the time period available for foraging at sea $\left(>2^{\circ} \mathrm{C}\right)$ ranges from a few weeks to several months, motivating two research questions: 1) Is population structure compatible with possibilities for evolutionary rescue of anadromous populations during climate change? 2) Does selection associated with latitude or SST regimes act on phenology-related loci? In Western Greenland, strong isolation-by-distance at SNPs was observed and spatial autocorrelation analysis showed genetic patch size up to $450 \mathrm{~km}$, documenting contingency and gene flow among populations. Outlier tests provided no evidence for selection at phenology-related loci. However, in Western Greenland, mean allele length at OtsClocklb was positively associated with the time of year when SST first exceeded $2^{\circ} \mathrm{C}$ and negatively associated with duration of the period where SST exceeded $2^{\circ} \mathrm{C}$. This is consistent with local adaptation for making full use of the time period available for foraging in the sea. Current adaptation may become maladaptive under climate change, but long-distance connectivity of anadromous populations could redistribute adaptive variation across populations and lead to evolutionary rescue.

Key Words: Arctic char, climate change, clock gene, phenology, sea surface temperature, spatial 
63

64

65

66

67

68

69

70

71

72

73

\section{Introduction}

Ongoing anthropogenic climate change has the potential to profoundly affect the living conditions of biota, involving e.g. physiological stress during warm periods, altered ecological interactions and colonization of new species (Hoffmann and Sgro 2011; Parmesan 2006; Pörtner and Peck 2010; Thackeray et al. 2016). A much debated issue concerns whether or not organisms are able to respond to rapid climate change by genetically based microevolution or have to rely on phenotypic plasticity (Hansen et al. 2012; Hoffmann and Sgro 2011; Merila and Hendry 2014). Crozier and Hutchings (2014) found that very few studies of fishes had documented adaptive change that could be ascribed to changing climate, with a few notable exceptions such as a study of altered migration timing in pink salmon (Oncorhynchus gorbuscha) (Kovach et al. 2012). Nevertheless, several studies have presented results consistent with adaptation to extant climate and temperature regimes in fishes at phenotypic traits and/or candidate genes that supposedly reflect evolution over longer time spans than those over which anthropogenic climate change occurs (Bernatchez 2016; Bradbury et al. 2010; Harrisson et al. 2017; Jensen et al. 2008; Koskinen et al. 2002; Narum et al. 2010;

Perrier et al. 2017). Adaptations to current climate conditions could become increasingly maladaptive as the climate changes, but could also act as a source of genetic variation for future evolutionary rescue, through the influx of genetic variation into populations via gene flow to allow adaptation to altered environmental conditions (Gonzalez et al. 2013).

It has been argued that in temperate and Arctic regions, the most pronounced changes to living conditions concern altered seasonal timing, including later arrival of winter and earlier arrival of spring, rather than increased temperature per se (Bradshaw and Holzapfel 2006, 2008). This means that phenological traits, such as timing of migration and reproduction, may be particularly important for the future persistence of organisms. Many phenological traits are regulated by an internal clock that is synchronized particularly by photoperiods and temperature. A core set of genes form and regulate the circadian clock system across vertebrate taxa: Clock, Bmal, Period and Cryptochrome (Idda et al. 2012; Lincoln et al. 2003; Lowrey and Takahashi 2004). Clock, in particular, has received considerable attention. A critical domain in this gene is the carboxyl-terminal polyglutamine repeat motif (polyQ), in which increases and decreases in the number of polyQ repeats affect gene expression (Darlington et al. 1998; Hayasaka et al. 2002). Several studies of birds have revealed positive associations between clock (polyQ) allele lengths and breeding latitude (Bazzi et al. 2016; Johnsen et al. 2007), but also examples of no association in some species (Dor et al. 2012). 
The salmonid fish clock gene OtsClocklb has similarly been found to be associated with variation in run time and/or latitudinal gradient in Chinook salmon (Oncorhynchus tshawytscha), Chum salmon (O. keta), and Atlantic salmon (Salmo salar) (O'Malley and Banks 2008; O'Malley et al. 2014; O'Malley et al. 2010a; O'Malley et al. 2013). Furthermore, the gene localizes to a QTL (quantitative trait locus) region for spawning time and developmental growth in Coho salmon $(O$. kisutch) and Rainbow trout (O. mykiss) (Leder et al. 2006; O'Malley et al. 2010a). Nevertheless, in Coho (O. kisutch) and Pink salmon (O. gorbuscha) along with the non-salmonid Threespine stickleback (Gasterosteus aculeatus), no association between clock polyQ variation, latitudinal gradients and spawning time has been observed (Kovach et al. 2012; O'Brien et al. 2013; O'Malley et al. 2010a). In Coho and Pink salmon, however, this was in fact a predicted result as these species show minimal geographical variation in age at spawning and time of spawning (O'Malley et al. 2010a). clock is therefore a potentially important candidate gene for migratory and reproductive phenological traits in many, but not all fishes, and could be an important target for monitoring adaptive responses to climate change (Hansen et al. 2012).

Arctic regions are particularly affected by climate change (Leduc et al. 2016). For instance, the decade from 2001-2010 was the warmest period on record in Greenland from 1784 to the present and by 2050 temperature is projected to have increased by $3^{\circ} \mathrm{C}$ in winter, $4^{\circ} \mathrm{C}$ in spring and $2^{\circ} \mathrm{C}$ in summer and autumn (Cappelen and Vinther 2014). Arctic char (Salvelinus alpinus) is a cold wateradapted salmonid widely distributed in the northern circumpolar Arctic region (Klemetsen et al. 2003), and in Greenland anadromous populations are found throughout coastal regions. They exhibit a complex life-history involving repeat spawning interrupted by years of no spawning. It is generally assumed that anadromous populations spawn around October (Klemetsen et al. 2003). Due to logistic constraints, no systematic records of spawning time are available for Arctic char in Greenland. However, ripe and spent spawners were observed in late September - early October in Southern Greenland during the course of the present study, and it is assumed that spawning takes place earlier in more northern regions.

Both spawning and non-spawning anadromous char overwinter in freshwater, the latter presumably in order to avoid osmotic stress in the marine environment during cold Arctic winters (Klemetsen et al. 2003; Moore et al. 2017). Experimental work by Finstad et al. (1989) demonstrated osmotic stress and high mortality when Arctic char were exposed to high salinity and a temperature of $1^{\circ} \mathrm{C}$ 
128 during winter, but not when they were exposed to the same conditions during summer. This

129 suggests that complex interactions exist between osmoregulatory capacity and seasonal change,

130 possibly regulated by photoperiod. In general, the total length of the season that anadromous Arctic

131 char are able to spend foraging at sea, as determined by the sea temperature, is assumed to be a

132 critical parameter determining growth and life history (Dutil 1986). Greenlandic anadromous char

133 populations are distributed at a range of more than 20 latitudinal degrees, implying that

134 considerable geographical variation in the length of the growth season must be expected, leading to 135 the possibility of local adaptation of associated phenological traits.

The goal of this study was to address two key research questions: 1) Is the genetic structure and differentiation among anadromous populations compatible with possibilities for evolutionary rescue during climate change? 2) Does selection associated with latitude or marine temperature regimes act on the phenology-related markers? Toward this end, the genetic structure of anadromous char populations in Western Greenland were analyzed along with "outgroup" populations from Eastern Greenland, Iceland and Norway, the latter two represented by landlocked lake populations. Two data sets of fifty-three presumably neutral SNPs (single nucleotide polymorphisms) and four phenology-related loci (OtsClock1b, Ots515NWFSC, Cryptochrome2b.2 and Cryptochrome3), respectively, were analyzed in 18 populations. Moreover, remotely sensed data were extracted on sea surface temperature close to the mouths of the sampled rivers and lakes to estimate the onset, end, and duration of the periods of time that local populations could potentially spend at sea.

Materials and Methods

$\underline{\text { Samples }}$

151 Adipose fin clips were collected from 2005-2016 by angling, net fishing and electrofishing. We 152 aimed for sample sizes of twenty, as higher sample sizes generally do not improve estimates of standard population genetic statistics as compared to increasing number of loci (Takezaki and Nei 1996). Among the 18 populations included in the study, 15 were anadromous populations located along the West coast of Greenland. Three additional populations represented anadromous char from

156 Eastern Greenland and two landlocked lake populations from Iceland and Norway (see Fig. 1 and 157 Table 1). Collection and handling of samples in Greenland took place according to survey licenses G14-034 and G15-013 from the Government of Greenland. 


\section{Molecular analyses}

161 DNA was extracted using the E.Z.N.A DNA Tissue Extraction Kit (Omega Bio-Tek, Norcross, 162 USA) according to the manufacturer's recommendations. Two sets of loci were analyzed: 1) 53 163 single nucleotide polymorphisms (SNPs) developed for Arctic char (Jacobsen et al. 2017) and 164 assumed to represent neutral markers as based on outlier tests conducted in Christensen et al. 165 (2018), and 2) four candidate loci assumed to be involved in phenology. SNPs were genotyped on a 16696.96 Dynamic Array on the Fluidigm Biomark platform (Fluidigm Corporation, San Francisco, 167 USA). As explained in Jacobsen et al. (2017) the initial set consisted of 96 SNPs, of which 43 could 168 not be scored reliably due particularly to the presence of paralogs presumably resulting from ancient 169 tetraploidy in salmonid fishes (Allendorf et al. 2015). Genotypes were scored using the associated 170 Fluidigm ${ }^{\circledR}$ SNP Genotyping Analysis software.

172 The candidate loci consisted of the polyQ region of the Clock gene OtsClocklb, microsatellites 173 closely linked to the two duplicated copies Cryptochrome2b.2 and Cryptochrome 3 of the circadian 174 rhythm gene Cryptochrome, and a microsatellite Ots515NWFSC, which is a QTL for spawning time and body weight in rainbow trout (O'Malley et al. 2003). Primer sequences for the loci are described in Naish and Park (2002), O'Malley et al. (2007) and O'Malley et al. (2010b). The forward primers of OtsClock1b, Ots515NWFSC, Crytochrome2b.2 and Cryptochrome3 were labeled with the fluorescent dyes PET, NED, FAM and VIC, respectively. The loci were PCR amplified at an annealing temperature of $55 \mathrm{C}$ in $30 \mu 1$ reactions containing $15 \mu$ QIAGEN Multiplex PCR Mastermix (QIAGEN, Hilden, Germany), $3 \mu 1100 \mu \mathrm{M}$ primer mix; $10 \mu 1$ fluorescently labeled primer and $10 \mu 1$ reverse primer, $11 \mu 1 \mathrm{H}_{2} \mathrm{O}$ and $1 \mu 1$ sample DNA (concentrations between ca. 80 and $400 \mathrm{ng} / \mu \mathrm{l}$ ). Genotyping was outsourced to Macrogen Inc.

183 (Seoul, Korea), where fragments were resolved on an ABI 3730XL capillary sequencer using a 600

184 LIZ internal size standard (Applied Biosystems, Cheshire, UK). Scoring of genotypes was conducted using the software Geneious 10.0.7 (Kearse et al. 2012).

Salmonid fishes are ancient tetraploids, and simple Mendelian inheritance cannot always be assumed (Allendorf et al. 2015; Allendorf and Thorgaard 1984). Also, scoring of multiallelic loci may in itself be complicated. In order to validate Mendelian inheritance and scoring of the phenology-related loci, two full-sib family crosses were therefore established, based on two males 
191 and two females sampled in October 2013 in the NUUK-2 population (see Table 1 and Fig. 1).

192 Fertilized eggs were incubated in Petri dishes at $5 \mathrm{C}$ following Wedekind and Muller (2004). This

193 took place at the Greenland Institute of Natural Resources, Nuuk, where Petri dishes were inspected

194 daily, and upon hatching the larvae were euthanized and stored in $96 \%$ ethanol at $-18 \mathrm{C}$. The

195 parents and 10 offspring from each family were genotyped.

196

197 Genetic population structure

198 For all analyses of population structure, SNPs and candidate loci were analyzed separately. Mean

199 heterozygosity was estimated using GENEPOP version 4.2 (Rousset 2008) and the same software

200 was used to test for Hardy-Weinberg equilibrium at all loci in all populations. Genetic

201 differentiation for the two datasets was analyzed by 1) an AMOVA (Analysis of Molecular

202 Variance) involving all populations and 2) a hierarchical AMOVA involving populations from

203 Western Greenland, as implemented in ARLEQUIN version 3.5.2.2 (Excoffier et al. 2005). For this

204 study, five regional groups of Western Greenland populations were defined by the geographical

205 location of populations: region 1 (UUMM-1, UUMM-2 and DISK-1), region 2 (KANG-1 and SISI-

206 1), region 3 (MANI-1 and MANI-2), region 4 (NUUK-1, NUUK-2, NUUK-3, NUUK-4 and

207 NUUK-5), region 5 (QAQO-1 and QAQO-2). The geographically remote QAAN-1 population

208 could not be meaningfully included in a regional group with other populations and was omitted

209 from this analysis. Finally, $\mathrm{F}_{\mathrm{ST}}$ between all pairs of populations was estimated, also using

210 ARLEQUIN.

212 The genetic relationships among populations at the SNPs were further analyzed by DAPC

213 (Discriminant Analysis of Principal Components) (Jombart et al. 2010), implemented in the R

214 package adegenet (Jombart 2008). Briefly, the method defines clusters of individuals without prior

215 knowledge of their sample of origin and identifies discriminant functions that distinguish clusters

216 while at the same time minimizing variation within clusters. We first identified the most likely

217 number of clusters and the individuals belonging to them based on k-means clustering and Bayesian

218 Information Criterion, followed by choosing the optimal number of principal components (using

219 cross-validation) and discriminant axes, as detailed in the documentation for DAPC.

221 Isolation-by-distance (IBD) for the two classes of markers was tested using Mantel tests

222 implemented in the software Isolation-By-Distance, web service version 3.23 (Jensen et al. 2005). 
223 Pairwise $\mathrm{F}_{\mathrm{ST}}$ estimates were used as genetic distance, and geographical distance (shortest waterway distance) was estimated using Google Earth. Moreover, IBD was visualized by geneticgeographical distance scatter plots along with their regression lines and 95\% confidence intervals. The analyses focused exclusively on the 15 populations from Western Greenland (i.e. excluding the geographically distant SCOR-1, ICEL-1 and NORW-1 populations).

Finally, we used spatial autocorrelation analysis (Sokal and Oden 1991) implemented in GenAlEx 6.5 (Peakall and Smouse 2006, 2012; Smouse and Peakall 1999) in order to assess the geographical scale in Western Greenland over which individual genotypes show non-random association. This was based on all pairwise individual genetic distances (Smouse and Peakall 1999) and a corresponding geographical distance matrix based on waterway distances between sites, as described for the isolation-by-distance analyses. We assumed a geographical distance of 0 for individuals from the same rivers. In order to balance the number of individuals within geographical distance classes we assumed classes with increments of $50 \mathrm{~km}$ from 0 to 500 , and subsequently with increments of $500 \mathrm{~km}$. Both the $95 \%$ confidence interval of distance-class specific $\mathrm{r}$ values and the $95 \%$ confidence interval in case of no spatial structure of individuals were estimated by bootstrapping over pairs of individuals 9999 times.

surface temperature data

Remotely sensed sea surface temperature data (in the following denoted SST), encompassing a resolution of 0.25 degree latitude $\mathrm{x} 0.25$ degree longitude on a global grid and measured for each

244 day were provided by the NOAA/OAR/ESRL PSD, Boulder, Colorado, USA, from their Website at http://www.esrl.noaa.gov/psd/. Data from 1984, 1994, 2004 and 2014 were used, hence covering temperatures for a time span of 40 years. Data for each day of the year from the position closest to the sampled river/lake mouths inhabited by anadromous char (hence excluding the resident

248 populations ICEL-1 and NORW-1) were retrieved using the function extractOISSTdaily from the R 249 script NOAA_OISST_ncdf4.R (http://lukemiller.org/index.php/2014/11/extracting-noaa-seasurface-temperatures-with-ncdf4/). Subsequently, the mean temperature per day over the total time period was calculated. As anadromous char experience osmotic stress at $1^{\circ} \mathrm{C}$ (Finstad et al. 1989),

$252 \mathrm{SST}<2^{\circ} \mathrm{C}$ was tentatively defined as unfavorable to char in the sea. For each locality the time period (in the following denoted SST window) was estimated during which SST was $\geq 2{ }^{\circ} \mathrm{C}$. The 
254 start and end-points of the SST-window, measured in numbers of days starting from 1 January, and 255 the duration of the SST-window were subsequently used for some of the selection tests (see below).

\section{Selection tests}

258 Outlier tests implemented in ARLEQUIN (Excoffier et al. 2009) were used for assessing possible 259 selection at the phenology-related loci, with the SNP data set included to provide a putatively 260 neutral baseline of differentiation (Christensen et al. 2018). The first, involving all populations was 261 the $\mathrm{F}_{\mathrm{ST}}$-based test by Beaumont and Nichols (1996). The second was an extension of this test by 262 Excoffier et al. (2009), which takes underlying hierarchical structure of populations into account.

263 The latter test was based on the same populations and regional groups in Western Greenland as 264 described for the hierarchical AMOVA (see above). The analyses were based on 10,000 265 simulations.

267 A third outlier test was conducted, i.e. BAYESCENV (de Villemereuil et al. 2015) which tests for association between loci and environmental parameters. It is an extension of the outlier test BAYESCAN (Foll and Gaggiotti 2008) and distinguishes between 1) neutrality, 2) a locus-specific effect, possibly representing selection but not associated with the environmental parameter tested and 3) an effect of the environmental parameter on a specific locus which could represent selection. The total set of SNPs and phenology-related loci were included, and the environmental parameters tested were the start dates, end dates and duration of SST windows, along with latitude of the sample localities. The recommended default settings of the program were used ( 20 pilot runs each consisting of 2,000 steps, burn-in of 50,000 steps followed by 50,000 steps and a thinning interval size of 10).

Finally, we tested for an association between mean allele lengths (assumed to represent polyQ copy number variation) in populations at OtsClock $1 b$ and 1) latitude, 2) start, 3) end dates and 4) duration 280 of SST windows, using linear models (as in e.g. O'Malley and Banks (2008)) implemented in R (R 281 Core Team 2018).

\section{Results}


286 The experimental crosses were informative for resolving inheritance except for Cryptochrome2b.2

287 (Supporting Information, Table S1). At Ots515NWFSC and OtsClock1b all genotypes of parents 288 and offspring were congruent, whereas only a single heterozygote at Cryptochrome 3 occurred in 289 one parent, although the offspring showed the expected genotypes. Although sample sizes were too 290 low for statistical testing, the results nevertheless lend support for correct scoring of genotypes and 291 simple Mendelian inheritance at three of the four loci.

293 Summary statistics and genetic population structure

294 Among 18603 genotypes in the SNP data set (351 individuals x 53 loci) only 57 could not be 295 resolved, leading to $0.3 \%$ missing data. Estimated mean heterozygosity across SNPs per population 296 varied from 0.06 (NORW-1) to 0.32 (SISI-1). There was a distinct pattern of lower heterozygosity 297 in the landlocked populations ICEL-1 and NORW-1 along with the Eastern Greenland population 298 SCOR-1 as compared to the anadromous populations from Western Greenland ( $\mathrm{p}<0.001$ as 299 determined by a permutation test in FSTAT 2.9.3 (Goudet 1995); see also Table 1 and Supporting 300 Information, Table S2). The phenology-related loci encompassed 1404 genotypes (351 individuals $301 \mathrm{x} 4$ loci), of which only $13(0.9 \%)$ could not be resolved. Estimated mean heterozygosity across 302 phenology-related loci ranged from 0.18 (QAAN-1) to 0.65 (MANI-2) (Table 1, Supporting 303 Information, Table S2). In contrast to SNPs these loci were all multiallelic with numbers of alleles 304 ranging from 4 to 24 per locus (Supporting Information, Table S2). Three out of a total of 741 tests 305 for Hardy-Weinberg equilibrium yielded significant outcomes $(\mathrm{p}<0.001)$ after False Discovery Rate 306 (FDR) correction by the B-Y method (Narum 2006) (Supporting Information, Table S2). Hence, 307 the populations can be assumed to be in Hardy-Weinberg equilibrium.

309 Overall genetic differentiation $\left(\mathrm{F}_{\mathrm{ST}}\right)$ across all populations and over all SNPs was $0.27(\mathrm{p}<0.001)$.

310 The hierarchical AMOVA involving only Western Greenland populations showed that the largest 311 part of differentiation was distributed among geographic groups of populations $\left(\mathrm{F}_{\mathrm{CT}}=0.11, \mathrm{p}<\right.$ 312 0.001), whereas a relatively smaller part was distributed among populations within geographic 313 groups $\left(\mathrm{F}_{\mathrm{SC}}=0.09, \mathrm{p}<0.001\right)$. Genetic differentiation at phenology-related loci was similar, with 314 overall $\mathrm{F}_{\mathrm{ST}}=0.23(\mathrm{p}<0.001)$ across all populations. For the hierarchical AMOVA $\mathrm{F}_{\mathrm{CT}}$ was $0.10(\mathrm{p}$ $315<0.001)$ and $\mathrm{F}_{\mathrm{SC}}$ was $0.06(\mathrm{p}<0.001)$. $\mathrm{F}_{\mathrm{ST}}$ between pairs of populations for the SNP dataset ranged 316 from 0.02 (NUUK-2 versus NUUK-3 and NUUK-2 versus NUUK-4) to 0.67 (QAAN-1 versus 
317 NORW-1), whereas for the phenology-related loci $\mathrm{F}_{\mathrm{ST}}$ ranged from 0.02 (several pairs of 318 populations) to 0.47 (QAAN-1 versus SCOR-1; Supporting Information, Table S3).

320 For the DAPC analysis of the SNP data, the most likely number of groups represented by the 321 individual multi-locus genotypes was 9, as determined by the Bayesian Information Criterion (see 322 Supporting Information, Fig. S1). Grouping of individuals (Fig. 2.a) showed that the northernmost 323 populations (QAAN-1, UUMM-1, UUMM-2, DISK-1) were composed of three clusters (Cluster 1, 3247 and 9), and individuals from KANG-1 belonged exclusively to Cluster 2. Individuals from the populations SISI-1, MANI-1, MANI-2, NUUK-1, NUUK-2, NUUK-3, NUUK-4 and NUUK-5 were distributed across Clusters 1, 2, 3, 4, 5, 6, 7, and 8. QAQO-1 individuals were exclusively assigned to Cluster 8, whereas QAQO-2 individuals were assigned to Clusters 3 and 8. Finally, all individuals from SCOR-1, ICEL-1 and NORW-1 were assigned to Cluster 3. The first 25 Principal Components and 7 discriminant axes were retained for the DAPC scatterplot. Axes 1 and 2 (Fig. 2.b) demonstrated a strong geographic structure among the nine inferred clusters, with Clusters 9,1 and 7 (northernmost populations in Western Greenland) representing one end of a continuum and Cluster 3 (Southwestern and Eastern Greenland, Iceland and Norway) representing the other end. Hence, the results of DAPC showed good correspondence with the geographical location of populations, justifying the groupings of populations used for the hierarchical AMOVA.

The close relationships between geographical and genetic relationships were further illustrated for both SNPs and candidate loci by analysis of isolation-by-distance involving only the anadromous Western Greenland populations (Fig. 3.a and b). Hence, there was significant correlation between genetic differentiation and geographical distance for SNPs $\left(R^{2}=0.92, p=0.0000\right)$ and for phenology-related loci $\left(\mathrm{R}^{2}=0.55, \mathrm{p}=0.0000\right)$.

The spatial autocorrelation analysis (Fig. 4) showed a mean correlation among individuals from the same freshwater localities of 0.330 and subsequently declined and reached its first intercept with the $\mathrm{x}$-axis at $450 \mathrm{~km}$. This value is usually referred to as the genetic patch size (Smouse and Peakall 1999; Sokal and Wartenberg 1983). Using distance classes of $100 \mathrm{~km}$ instead of $50 \mathrm{~km}$ yielded a similar genetic patch size (data not shown).

\section{$\underline{\text { Sea surface temperature data }}$}


349 Sea surface temperature (SST) data were retrieved from all coastal regions close to the river mouths 350 of the sampled anadromous populations. In the case of NUUK-2, NUUK-3, NUUK-4, and NUUK-5 351 the geographical distances between river mouths were short. Therefore, these populations shared the 352 same pixel of the SST grid and thereby similar temperature regimes. The SST windows, defined by 353 the time periods during the year when SST exceeded $2{ }^{\circ} \mathrm{C}$, varied considerably across populations 354 (Fig. 5, Supporting Information, Table S4). Hence, SST exceeded $2^{\circ} \mathrm{C}$ for only a few weeks in the 355 northernmost populations QAAN-1, UUMM-1, UUMM-2 and in SCOR-1 from Eastern Greenland 356 (Fig. 5.a, b, c and m). In contrast, SST exceeded $2^{\circ} \mathrm{C}$ for several months in most of the other 357 populations, potentially leaving longer time periods for Arctic char to forage in the sea. The lower 358 temperatures in the south-western localities QAQO-1 and QAQO-2 (Fig. 5.k and 1) as opposed to 359 the more northern localities DISK-1, SISI-1, KANG-1, MANI-1, MANI-2 and NUUK-1 to 5 (Fig. 360 5.d to j) reflects the influence of the West Greenland Current (Lloyd et al. 2007). Hence, variation 361 in SST windows did not merely reflect latitudinal variation.

\section{Selection tests}

364 The $\mathrm{F}_{\mathrm{ST}}$-based outlier test (Beaumont and Nichols 1996) involving all populations identified three SNPs (Contig7991, Contig11261 and Contig10740_78) to be high-divergence outliers, whereas seven SNPs and one phenology-related locus Ots515NWFSC showed lower $\mathrm{F}_{\mathrm{ST}}$ than expected under neutrality (Supporting Information, Fig. S2.a). The hierarchical outlier test (Excoffier et al. 2009) involving only populations from Western Greenland identified only Contig10740_78 as a

369 high divergence outlier, and also again identified Ots515NWFSC as a low divergence outlier along with two SNPs (Supporting Information, Fig. S2.b). The results for Ots515NWFSC are likely to reflect the higher allelic diversity (microsatellite; 24 alleles) relative to bi-allelic SNPs. Hence, its outlier status is assumed to represent differences in mutation rate between microsatellites and SNPs rather than evidence for balancing selection. The absence of clearly identifiable selection was also evident from the landscape outlier test analyses using the method by de Villemereuil et al. (2015). Hence, there were no significant associations between any of the loci and 1) latitude, 2) start of SST-window, 3) end of SST-window and 4) duration of SST-window. Also, none of the loci were outliers without association with environmental parameters (data not shown). In order to rule out that there was an issue with including highly polymorphic loci and bi-allelic SNPs in the outlier tests, they were repeated including only Cryptochrome3 and OtsClock1b (each showing four 
380 alleles) along with the SNPs. However, this did not lead to identification of more outliers (data not 381 shown).

383 The above outlier tests only consider allele frequencies, whereas functional variation at OtsClock1b 384 consists of the number of polyQ repeats, that is, the length of alleles. At the scale of all populations 385 (landlocked and anadromous) there was no significant association between mean allele length at 386 OtsClock1b and latitude (Table 2; Supporting Information Fig. S3.a), and this was also the case at 387 the scale of all anadromous populations from Greenland and at the scale of anadromous populations 388 from Western Greenland, i.e. omitting the population SCOR-1 from Eastern Greenland (see Table 389 2). Across all anadromous populations from Greenland, there was also no significant association 390 between mean allele length and both SST-window start date, end date, or duration (Table 2, 391 Supporting Information Fig. S3.b-d). At the scale of anadromous populations from Western 392 Greenland there was, however, a positive association between mean allele length and both SST393 window start date or duration (Table 2 and Supporting Information Fig. S3.e-f), though we note that 394 SST-window start date and duration were strongly correlated and hence cannot be considered independent $\left(\mathrm{y}=-0.567 \mathrm{x}+229.738, \mathrm{R}_{\text {adjusted }}=0.762, \mathrm{p}=1.38 \times 10^{-5}\right)$.

\section{Discussion}

398 Our results revealed a pattern of strong genetic differentiation among Arctic char populations 399 encompassing both anadromous and landlocked populations, and a distinct geographical structure 400 among Western Greenland anadromous populations. SST data suggested strong geographical 401 variation with respect to the time at which temperatures provided favourable conditions for 402 migration and foraging in the sea. Despite this variation providing different selection regimes acting 403 at phenological traits, evidence for selection acting on phenology-related loci was mixed. However, 404 in Western Greenland populations, a significant association was detected between mean allele 405 length at $O t s C l o c k 1 b$ and the start date or duration of the time window during which SST exceeded $4062^{\circ} \mathrm{C}$.

$408 \quad$ Genetic population structure

409 Although large-scale phylogeographical studies of Arctic char based on analysis of mitochondrial 410 DNA have been conducted previously (Brunner et al. 2001; Moore et al. 2015) and large scale 411 genetic differentiation among European landlocked char populations has been reported (Wilson et 
412 al. 2004), the present study represents a first assessment of genetic variation and structure at nuclear 413 loci in anadromous Arctic char on a large geographical scale. Genetic variation at SNPs was clearly 414 lower in the two landlocked populations than in the majority of anadromous populations, reflecting 415 well-established patterns of variation observed across marine, anadromous and freshwater fish 416 species and populations (Martinez et al. 2018; Ward et al. 1994).

418 Focusing exclusively on SNP variation in anadromous populations in Western Greenland, the 419 hierarchical AMOVA showed stronger differentiation among regional groups of populations as 420 compared to differentiation among populations within groups. Along with the distinct clustering of 421 populations according to geography in the DAPC analysis, the highly significant isolation by 422 distance and the outcome of the spatial autocorrelation analysis this provides evidence for a system 423 connected by gene flow and with geographical distance as a major factor influencing genetic 424 divergence. This could in principle represent a true hierarchical structure with distinct groups of 425 local populations, or it could represent a continuous structure with isolation by distance, with the seemingly hierarchical structure reflecting an artefact due to gaps in the geographical coverage of sampling. The fact that strong isolation by distance was observed and points did not separate into different clusters (Fig. 3.a), which could otherwise indicate genetic breaks, favours the latter option. As a whole, the genetic structure of anadromous char populations along the Western Greenland coast is congruent with previous studies focusing on smaller geographical regions (Bernatchez et al. 1998; Christensen et al. 2018; Harris et al. 2013; Harris et al. 2016; Moore et al. 2017; Moore et al. 2013).

Christensen et al. (2018) analyzed historical (DNA extracted from otoliths and scales from the 1950s) and contemporary samples from a subset of the anadromous populations included in this study (NUUK-1, NUUK-2, NUUK-4 and QAQO-2), and they found that the genetic structure was remarkably stable over time. Moreover, using a temporal method for estimating effective population 438 size $\left(\mathrm{N}_{\mathrm{e}}\right)$ and migration rate $(\mathrm{m})$ (Wang and Whitlock 2003), they found $\mathrm{N}_{\mathrm{e}}$ point estimates to 439 exceed 500 in most populations and $\mathrm{m}$ to be at most 0.058 . Based on the temporal stability, the 440 estimated $\mathrm{N}_{\mathrm{e}}$ and $\mathrm{m}$ values and a model incorporating the relative importance of genetic drift, gene 441 flow and strength of selection (Yeaman and Otto 2011) it was suggested that anadromous Arctic char populations have the potential to be locally adapted (Christensen et al. (2018); see also Moore et al. (2013) and Santaquiteria et al. (2016)). This is certainly likely to be the case for populations 
444 distributed across the $>1,500 \mathrm{~km}$ geographical span along the Western Greenland coast, 445 encompassing considerable climatic and other environmental variation. Climate change in the 446 Arctic is in general expected to lead to a northward shift of climate regimes, with southern 447 populations being adapted to climate conditions that more northern populations will experience in 448 the future, although the situation appears more complex for SST regimes and possible associated 449 adaptation (see below). Does this mean that possible adaptive genetic variation could move across 450 populations by gene flow, leading to future evolutionary rescue of populations maladapted to 451 altered climatic conditions (Gonzalez et al. 2013)? The pronounced isolation by distance suggests 452 that populations across the range are indeed connected. This is further supported by the genetic 453 patch size of $450 \mathrm{~km}$ estimated by spatial autocorrelation analysis; although it is difficult to 454 interpret this value directly in terms of gene flow, it does suggest connectivity among populations 455 over long geographical distances. Hence, evolutionary rescue is possible, although the results do not 456 inform about the rate at which beneficial variation for evolutionary rescue could disperse into 457 increasingly maladapted populations affected by climate change.

Variation at phenology-related loci

460 The Arctic char populations of this study represented habitats showing strong variation in latitude 461 and thereby photoperiod and sea-surface temperature, the latter visualized by SST-windows in Fig. 462 5. Although it is often argued that Arctic char have only a short annual period available for foraging 463 in the sea in some parts of their distribution range (Moore et al. 2017), in Greenland the time 464 periods where sea-surface temperature exceeded $2^{\circ} \mathrm{C}$ in fact varied from a few weeks to several 465 months, leaving ample opportunity for local adaptation to this crucial environmental factor. Yet, the evidence for selection acting on the phenology-related loci was mixed.

The outlier tests applied (Beaumont and Nichols 1996; de Villemereuil et al. 2015; Excoffier et al. 2009) suggested only one of the SNPs (Contig10740_78) to be a consistent high differentiation 470 outlier, and none of the phenology-related candidate loci were indicated to be under divergent 471 selection. It is possible that the choice of bi-allelic SNPs as supposedly neutral baseline loci was 472 suboptimal, as two of the phenology-related loci showed twenty-four (Ots515NWFSC) and seven 473 (Cryptochrome2b.2) alleles, respectively. On the other hand, Cryptochrome3 and OtsClock1b each 474 showed only four alleles and overall low heterozygosity within populations. Hence, using 475 multiallelic microsatellite loci as a neutral background would not have been appropriate in such 
cases. Therefore, it cannot be ruled out entirely that some of the loci are in reality under selection, but that the outlier tests failed to detect this.

The tests incorporating allele lengths at $O t s C l o c k 1 b$, thereby reflecting functional polyQ repeat variation, showed no significant association between mean allele length and latitude, as otherwise reported in Chinook and Chum salmon (O'Malley et al. 2010a; O'Malley et al. 2013). However, we did observe significant association between OtsClock1b mean allele length and start date of SSTwindow or total duration of the SST-window, whereas no association was revealed for SST-window end date. It is puzzling that the associations became non-significant when the geographically remote population SCOR-1 from Eastern Greenland was included. One possibility may be due to phylogeographic complexity; mitochondrial DNA representing the two distinct Arctic and Atlantic phylogeographic lineages have previously been documented in Western Greenland, presumably reflecting postglacial secondary contact (Brunner et al. 2001; Moore et al. 2015). Preliminary results based on mitogenome sequencing suggest that SCOR-1 belongs exclusively to the Atlantic lineage and hence allele lengths at OtsClock1b might not be functionally equivalent to alleles from Western Greenland (where both the Arctic and Atlantic phylogeographic lineages are found). A second possibility is that the sea surface temperature regime in SCOR-1 is distinctly different and not comparable to those of Western Greenland populations, as the start date of the SST-window is considerably later than in other populations (Fig. 5, Supporting Information, Table S4).

Under the assumption that the association between OtsClock1b mean allele length and start date of SST-windows represents a genuine biological signal, then this would suggest adaptation to emigrate from freshwater to the sea at the time that marine temperature regimes become favourable. Such adaptations would be highly important for making full use of the potential for foraging in the sea, a crucial factor in growth and survival (Jensen et al. 2018). Whereas there was also a significant association between mean allele length SST-window duration, the strong correlation between start date and SST-window duration raises questions about the specific parameter involved. The duration of SST-window is defined by the start and end date of the window, and as there was no significant association between mean allele length and end date, then this would suggest that it is really the start date that is the parameter of biological significance. 
507 It is somewhat surprising that no association was found with end date of SST-window, as studies of 508 other salmonids have documented association between OtsClocklb and run and/or spawning time 509 variation (O'Malley et al. 2014; O'Malley et al. 2010a; O'Malley et al. 2013). However, most SST510 window end dates occurred later than the assumed time of spawning; in some cases (QAQO-1 and 511 QAQO-2) as late as mid-November, whereas spawning is expected to take place no later than early 512 October. The optimal time of spawning must be assumed to be primarily determined by 513 temperature, waterflow and other factors in the freshwater environments although conditions in the 514 sea might also play a role, such as temperature affecting maturation. Hence, specific data on 515 spawning time would be required for directly testing its association with OtsClock1b variation.

517 In total, the results did not show association between OtsClock1b allele length and latitude, but 518 rather an association with SST-regimes. Due to the influence of the West Greenland Current (Lloyd 519 et al. 2007) SST-regimes do not simply reflect latitude, but are generally highest in a broad region 520 ranging from NUUK-1-5 to DISK-1 (see Fig. 1). It is possible that for other traits and genes 521 associated with selection in the freshwater environments, more clear-cut association with latitudinal variation would be found.

\section{Conclusions}

The study documented strong genetic differentiation among Arctic char, including the most intensively sampled region along the Greenland West Coast. A significant pattern of isolation-bydistance was observed among Western Greenland anadromous populations, indicating connectivity and an absence of clear genetic breaks. At most phenology-related loci, no evidence for selection was observed, but in Western Greenland anadromous populations association was observed between mean allele length at OtsClocklb and the start date of the time window during which sea surface temperature exceeded $2^{\circ} \mathrm{C}$, along with the duration of this time window. This suggests potentially important adaptations to geographical variation in sea surface temperatures and the optimal time of year for migrating to sea. At the same time, ongoing climate change is expected to affect sea surface temperature regimes, possibly causing current adaptations to become maladaptive in the future. The occurrence of gene flow among anadromous populations would facilitate redistribution of functionally important alleles at OtsClock $1 b$ across populations, e.g. from the populations DISK-1, KANG-1 and SISI-1 experiencing early onset of the SST-window, towards northern populations like UUMM-1, UUMM-2 and QAAN that currently are subject to late onset of the SST-window but may experience future earlier onset as a result of climate change. Hence, this 
could provide possibilities for evolutionary rescue in a rapidly changing environment, at least for phenological traits.

\section{Conflict of Interest Statement}

The authors declare no conflict of interest.

\section{Data Availability Statement}

Raw genotype data in Genepop format have been deposited in DRYAD doi:10.5061/dryad.sc30mr1 (Madsen et al. 2019).

\section{References}

Allendorf, F.W., Bassham, S., Cresko, W.A., Limborg, M.T., Seeb, L.W. \& Seeb, J.E. 2015. Effects of crossovers between homeologs on inheritance and population genomics in polyploid-derived salmonid fishes. Journal of Heredity 106: 217-227.

Allendorf, F.W. \& Thorgaard, G.H. 1984. Tetraploidy and the evolution of salmonid fishes. In: Turner, B.J., ed. Evolutionary Genetics of Fishes. New York: Plenum Press, pp. 55-93.

Bazzi, G., Cecere, J.G., Caprioli, M., Gatti, E., Gianfranceschi, L., Podofillini, S., Possenti, C.D., Ambrosini, R., Saino, N., Spina, F. \& Rubolini, D. 2016. Clock gene polymorphism, migratory behaviour and geographic distribution: a comparative study of trans-Saharan migratory birds. Molecular Ecology 25: 6077-6091.

Beaumont, M.A. \& Nichols, R.A. 1996. Evaluating loci for use in the genetic analysis of population structure. Proceedings of the Royal Society of London, Series B: Biological Sciences 263: 1619-1626.

Bernatchez, L. 2016. On the maintenance of genetic variation and adaptation to environmental change: considerations from population genomics in fishes. Journal of Fish Biology 89: 2519-2556.

Bernatchez, L., Dempson, J.B. \& Martin, S. 1998. Microsatellite gene diversity analysis in anadromous arctic char, Salvelinus alpinus, from Labrador, Canada. Canadian Journal of Fisheries and Aquatic Sciences 55: 1264-1272.

Bradbury, I.R., Hubert, S., Higgins, B., Borza, T., Bowman, S., Paterson, I.G., Snelgrove, P.V.R., Morris, C.J. \& Gregory, R.S. 2010. Parallel adaptive evolution of Atlantic cod on both sides of the Atlantic Ocean in response to temperature.

Proceedings of the Royal Society of London, Series B: Biological Sciences 277: 37253734. 
576 Bradshaw, W.E. \& Holzapfel, C.M. 2006. Climate change - Evolutionary response to rapid climate change. Science 312: 1477-1478.

578 Bradshaw, W.E. \& Holzapfel, C.M. 2008. Genetic response to rapid climate change: it's seasonal timing that matters. Molecular Ecology 17: 157-166.

Brunner, P.C., Douglas, M.R., Osinov, A., Wilson, C.C. \& Bernatchez, L. 2001. Holarctic phylogeography of Arctic charr (Salvelinus alpinus L.) inferred from mitochondrial DNA sequences. Evolution 55: 573-586.

Cappelen, J. \& Vinther, B.M. 2014. SW Greenland temperature data 1784-2013. Technical Report from the Danish Meteorological Institute 14-06 No. 06. Copenhagen, Denmark. Retrieved from http://www.dmi.dk/fileadmin/Rapporter/TR/tr14-06.pdf.

Christensen, C., Jacobsen, M.W., Nygaard, R. \& Hansen, M.M. 2018. Spatiotemporal genetic structure of anadromous Arctic char (Salvelinus alpinus) populations in a region experiencing pronounced climate change. Conservation Genetics 19: 687-700.

Crozier, L.G. \& Hutchings, J.A. 2014. Plastic and evolutionary responses to climate change in fish. Evolutionary Applications 7: 68-87.

Darlington, T.K., Wager-Smith, K., Ceriani, M.F., Staknis, D., Gekakis, N., Steeves, T.D.L., Weitz, C.J., Takahashi, J.S. \& Kay, S.A. 1998. Closing the circadian loop: CLOCK-induced transcription of its own inhibitors per and tim. Science 280: 15991603.

de Villemereuil, P., Gaggiotti, O.E. \& O'Hara, R.B. 2015. A new FST-based method to uncover local adaptation using environmental variables. Methods in Ecology and Evolution 6: 1248-1258.

Dor, R., Cooper, C.B., Lovette, I.J., Massoni, V., Bulit, F., Liljesthrom, M. \& Winkler, D.W. 2012. Clock gene variation in Tachycineta swallows. Ecology and Evolution 2: 95-105.

Dutil, J.D. 1986. Energetic constraints and spawning interval in the anadromous Arctic Charr (Salvelinus alpinus). Copeia: 945-955.

Excoffier, L., Guillaume, L. \& Schneider, S. 2005. Arlequin (version 3.0): An integrated software package for population genetics data analysis. Evolutionary Bioinformatics Online: 47-50.

Excoffier, L., Hofer, T. \& Foll, M. 2009. Detecting loci under selection in a hierarchically structured population. Heredity 103: 285-298.

Finstad, B., Nilssen, K.J. \& Arnesen, A.M. 1989. Seasonal changes in sea water tolerance of Arctic charr (Salvelinus alpinus). Journal of Comparative Physiology BBiochemical Systemic and Environmental Physiology 159: 371-378. 
611 Foll, M. \& Gaggiotti, O. 2008. A genome scan method to identify selected loci 612 appropriate for both dominant and codominant markers: a Bayesian perspective. 613 Genetics 180: 977-993.

614 Gonzalez, A., Ronce, O., Ferriere, R. \& Hochberg, M.E. 2013. Evolutionary rescue: an 615 emerging focus at the intersection between ecology and evolution. Philosophical Transactions of the Royal Society B-Biological Sciences 368: 20120404.

Goudet, J. 1995. FSTAT (Version 1.2): A computer program to calculate F-statistics. Journal of Heredity 86: 485-486.

Hansen, M.M., Waller, D.M., Olivieri, I., Nielsen, E.E. \& The Genetic Monitoring Group. 2012. Monitoring adaptive genetic responses to environmental change. Molecular Ecology 21:1311-1329.

Harris, L.N., Moore, J.-S., Galpern, P., Tallman, R.F. \& Taylor, E.B. 2013.

Geographic influences on fine-scale, hierarchical population structure in northern Canadian populations of anadromous Arctic Char (Salvelinus alpinus). Environmental Biology of Fishes 97: 1233-1252.

Harris, L.N., Moore, J.S., Bajno, R. \& Tallman, R.F. 2016. Genetic stock structure of anadromous Arctic char in Canada's Central Arctic: Potential implications for the management of Canada's largest Arctic char commercial fishery. North American Journal of Fisheries Management 36: 1473-1488.

Harrisson, K.A., Amish, S.J., Pavlova, A., Narum, S.R., Telonis-Scott, M., Rourke, M.L., Lyon, J., Tonkin, Z., Gilligan, D.M., Ingram, B.A., Lintermans, M., Gan, H.M., Austin, C.M., Luikart, G. \& Sunnucks, P. 2017. Signatures of polygenic adaptation associated with climate across the range of a threatened fish species with high genetic connectivity. Molecular Ecology 26: 6253-6269.

Hayasaka, N., LaRue, S.I. \& Green, C.B. 2002. In vivo disruption of Xenopus CLOCK in the retinal photoreceptor cells abolishes circadian melatonin rhythmicity without affecting its production levels. Journal of Neuroscience 22: 1600-1607.

Hoffmann, A.A. \& Sgro, C.M. 2011. Climate change and evolutionary adaptation. Nature 470: 479-485.

Idda, M.L., Bertolucci, C., Vallone, D., Gothilf, Y., Sanchez-Vazquez, F.J. \& Foulkes, N.S. 2012. Circadian clocks: Lessons from fish. Neurobiology of Circadian Timing 199: 41-57.

Jacobsen, M.W., Christensen, C., Madsen, R., Nygaard, R., Jonsson, B., Praebel, K. \& Hansen, M.M. 2017. Single nucleotide polymorphism markers for analysis of historical and contemporary samples of Arctic char (Salvelinus alpinus). Conservation Genetics Resources 9: 587-589.

Jensen, A.J., Finstad, B., Fiske, P., Forseth, T., Rikardsen, A.H. \& Ugedal, O. 2018. Relationship between marine growth and sea survival of two anadromous salmonid fish species. Canadian Journal of Fisheries and Aquatic Sciences 75: 621-628. 
650 Jensen, J.L., Bohonak, A.J. \& Kelley, S.T. 2005. Isolation by distance, web service. 651 Bmc Genetics 6: 13.

652 Jensen, L.F., Hansen, M.M., Pertoldi, C., Holdensgaard, G., Mensberg, K.-L.D. \& 653 Loeschcke, V. 2008. Local adaptation in brown trout early life-history traits: 654 implications for climate change adaptability. Proceedings of the Royal Society B: 655 Biological Sciences 275: 2859.

656 657 658 659

660 661

662 663 664

Johnsen, A., Fidler, A., Kuhn, S., Carter, K., Hoffmann, A., Barr, I., Biard, C., Charmantier, A., Eens, M. \& Korsten, P. 2007. Avian Clock gene polymorphism: evidence for a latitudinal cline in allele frequencies. Molecular Ecology 16: 48674880 .

Jombart, T. 2008. adegenet: a R package for the multivariate analysis of genetic markers. Bioinformatics 24: 1403-1405.

Jombart, T., Devillard, S. \& Balloux, F. 2010. Discriminant analysis of principal components: a new method for the analysis of genetically structured populations. Bmc Genetics 11: 94 .

Kearse, M., Moir, R., Wilson, A., Stones-Havas, S., Cheung, M., Sturrock, S., Buxton, S., Cooper, A., Markowitz, S., Duran, C., Thierer, T., Ashton, B., Meintjes, P. \& Drummond, A. 2012. Geneious Basic: An integrated and extendable desktop software platform for the organization and analysis of sequence data. Bioinformatics 28: 16471649.

Klemetsen, A., Amundsen, P.A., Dempson, J.B., Jonsson, B., Jonsson, N., O'Connell, M.F. \& Mortensen, E. 2003. Atlantic salmon Salmo salar L., brown trout Salmo trutta L. and Arctic charr Salvelinus alpinus (L.): a review of aspects of their life histories. Ecology of Freshwater Fish 12: 1-59.

Koskinen, M.T., Haugen, T.O. \& Primmer, C.R. 2002. Contemporary fisherian lifehistory evolution in small salmonid populations. Nature 419: 826-830.

Kovach, R.P., Gharrett, A.J. \& Tallmon, D.A. 2012. Genetic change for earlier migration timing in a pink salmon population. Proceedings of the Royal Society BBiological Sciences 279: 3870-3878.

Leder, E., Danzmann, R. \& Ferguson, M. 2006. The candidate gene, Clock, localizes to a strong spawning time quantitative trait locus region in rainbow trout. Journal of Heredity 97: 74-80.

Leduc, M., Matthews, H.D. \& de Elia, R. 2016. Regional estimates of the transient climate response to cumulative CO2 emissions. Nature Climate Change 6: 474-+.

Lincoln, G.A., Andersson, H. \& Loudon, A. 2003. Clock genes in calendar cells as the basis of annual timekeeping in mammals - a unifying hypothesis. Journal of Endocrinology 179: 1-13. 
Lloyd, J.M., Kuijpers, A., Long, A., Moros, M. \& Park, L.A. 2007. Foraminiferal reconstruction of mid- to late-Holocene ocean circulation and climate variability in Disko Bugt, West Greenland. Holocene 17: 1079-1091.

Lowrey, P.L. \& Takahashi, J.S. 2004. Mammalian circadian biology: Elucidating genome-wide levels of temporal organization. Annual Review of Genomics and Human Genetics 5: 407-441.

Madsen, R.A.P., Jacobsen, M.W., O’Malley, K.G., Nygaard, R., Præbel, K., Jónsson, B., Pujolar, J.M., Fraser, D.J., Bernatchez, L. \& Hansen, M.M. 2019. Data from: Genetic population structure and variation at phenology-related loci in anadromous Arctic char (Salvelinus alpinus). doi:10.5061/dryad.sc30mr1.

Martinez, A.S., Willoughby, J.R. \& Christie, M.R. 2018. Genetic diversity in fishes is influenced by habitat type and life-history variation. Ecology and Evolution 8: in press.

Merila, J. \& Hendry, A.P. 2014. Climate change, adaptation, and phenotypic plasticity: the problem and the evidence. Evolutionary Applications 7: 1-14.

Moore, J.S., Bajno, R., Reist, J.D. \& Taylor, E.B. 2015. Post-glacial recolonization of the North American Arctic by Arctic char (Salvelinus alpinus): genetic evidence ofmultiple northern refugia and hybridization between glacial lineages. Journal of Biogeography 42: 2089-2100.

Moore, J.S., Harris, L.N., Le Luyer, J., Sutherland, B.J.G., Rougemont, Q., Tallman, R.F., Fisk, A.T. \& Bernatchez, L. 2017. Genomics and telemetry suggest a role for migration harshness in determining overwintering habitat choice, but not gene flow, in anadromous Arctic Char. Molecular Ecology 26: 6784-6800.

Moore, J.S., Harris, L.N., Tallman, R.F. \& Taylor, E.B. 2013. The interplay between dispersal and gene flow in anadromous Arctic char (Salvelinus alpinus): implications for potential for local adaptation. Canadian Journal of Fisheries and Aquatic Sciences 70: $1327-1338$.

Naish, K.A. \& Park, L.K. 2002. Linkage relationship for 35 new microsatellite loci in chinook salmon Oncorhynchus tshawytscha. Animal Genetics 33: 312-327.

Narum, S.R. 2006. Beyond Bonferroni: Less conservative analyses for conservation genetics. Conservation Genetics 7: 783-787.

Narum, S.R., Campbell, N.R., Kozfkay, C.C. \& Meyer, K.A. 2010. Adaptation of redband trout in desert and montane environments. Molecular Ecology 19: 4622-4637.

O'Brien, C., Unruh, L., Zimmerman, C., Bradshaw, W.E., Holzapfel, C.M. \& Cresko, W.A. 2013. Geography of the circadian gene clock and photoperiodic response in western North American populations of the three-spined stickleback Gasterosteus aculeatus. Journal of Fish Biology 82: 827-839. 
O'Malley, K.G. \& Banks, M.A. 2008. A latitudinal cline in the Chinook salmon (Oncorhynchus tshawytscha) Clock gene: evidence for selection on PolyQ length variants. Proceedings of the Royal Society B-Biological Sciences 275: 2813-2821.

O'Malley, K.G., Camara, M.D. \& Banks, M.A. 2007. Candidate loci reveal genetic differentiation between temporally divergent migratory runs of Chinook salmon (Oncorhynchus tshawytscha). Molecular Ecology 16: 4930-4941.

O'Malley, K.G., Cross, T.F., Bailie, D., Carlsson, J., Coughlan, J.P., Dillane, E., Prodohl, P.A. \& McGinnity, P. 2014. Circadian clock gene (OtsClock1b) variation and time of ocean return in Atlantic salmon Salmo salar. Fisheries Management and Ecology 21: 82-87.

O'Malley, K.G., Ford, M.J. \& Hard, J.J. 2010a. Clock polymorphism in Pacific salmon: evidence for variable selection along a latitudinal gradient. Proceedings of the Royal Society B-Biological Sciences 277: 3703-3714.

O'Malley, K.G., Jacobson, D.P., Kurth, R., Dill, A.J. \& Banks, M.A. 2013. Adaptive genetic markers discriminate migratory runs of Chinook salmon (Oncorhynchus tshawytscha) amid continued gene flow. Evolutionary Applications 6: 1184-1194.

O'Malley, K.G., McClelland, E.K.\& Naish, K.A. 2010b. Clock genes localize to quantitative trait loci for stage-specific growth in juvenile coho salmon, Oncorhynchus kisutch. Journal of Heredity 101: 628-632.

O'Malley, K.G., Sakamoto, T., Danzmann, R.G. \& Ferguson, M.M. 2003. Quantitative trait loci for spawning date and body weight in rainbow trout: Testing for conserved effects across ancestrally duplicated chromosomes. Journal of Heredity 94: 273-284.

Parmesan, C. 2006. Ecological and evolutionary responses to recent climate change. Annual Review of Ecology Evolution and Systematics 37: 637-669.

Peakall, R. \& Smouse, P.E. 2006. GENALEX 6: genetic analysis in Excel. Population genetic software for teaching and research. Molecular Ecology Notes 6: 288-295.

Peakall, R. \& Smouse, P.E. 2012. GenAlEx 6.5: genetic analysis in Excel. Population genetic software for teaching and research-an update. Bioinformatics 28: 2537-2539.

Perrier, C., Ferchaud, A.L., Sirois, P., Thibault, I. \& Bernatchez, L. 2017. Do genetic drift and accumulation of deleterious mutations preclude adaptation? Empirical investigation using RADseq in a northern lacustrine fish. Molecular Ecology 26: 63176335 .

Pörtner, H.O. \& Peck, M.A. 2010. Climate change effects on fishes and fisheries: towards a cause-and-effect understanding. Journal of Fish Biology 77: 1745-1779.

R Core Team. 2018. R: A language and environment for statistical computing. $\mathrm{R}$ Foundation for Statistical Computing, Vienna, Austria. http://www.R-project.org/. 
760 Rousset, F. 2008. GENEPOP'007: a complete re-implementation of the GENEPOP 761 software for Windows and Linux. Molecular Ecology Resources 8: 103-106.

762

763

764

765

766

767

768

769

770

771

772

773

774

775

776

777

778

779

780

781

782

783

784

785

786

787

788

789

790

791

792

793

794

795

796

797
Santaquiteria, A., Svenning, M.A. \& Praebel, K. 2016. Contrasting levels of strays and contemporary gene flow among anadromous populations of Arctic charr, Salvelinus alpinus (L.), in northern Norway. Hydrobiologia 783: 269-281.

Smouse, P.E. \& Peakall, R. 1999. Spatial autocorrelation analysis of individual multiallele and multilocus genetic structure. Heredity 82: 561-573.

Sokal, R.R. \& Oden, N.L. 1991. Spatial Autocorrelation Analysis as an Inferential Tool in Population-Genetics. American Naturalist 138: 518-521.

Sokal, R.R. \& Wartenberg, D.E. 1983. A test of spatial autocorrelation analysis using an isolation-by-distance model. Genetics 105: 219-237.

Takezaki, N. \& Nei, M. 1996. Genetic distances and reconstruction of phylogenetic trees from microsatellite DNA. Genetics 144: 389-399.

Thackeray, S.J., Henrys, P.A., Hemming, D., Bell, J.R., Botham, M.S., Burthe, S., Helaouet, P., Johns, D.G., Jones, I.D., Leech, D.I., Mackay, E.B., Massimino, D., Atkinson, S., Bacon, P.J., Brereton, T.M., Carvalho, L., Clutton-Brock, T.H., Duck, C., Edwards, M., Elliott, J.M., Hall, S.J.G., Harrington, R., Pearce-Higgins, J.W., Hoye, T.T., Kruuk, L.E.B., Pemberton, J.M., Sparks, T.H., Thompson, P.M., White, I., Winfield, I.J. \& Wanless, S. 2016. Phenological sensitivity to climate across taxa and trophic levels. Nature 535: 241-245.

Wang, J.L. \& Whitlock, M.C. 2003. Estimating effective population size and migration rates from genetic samples over space and time. Genetics 163: 429-446.

Ward, R.D., Woodwark, M. \& Skibinski, D.O.F. 1994. A comparison of genetic diversity levels in marine, freshwater, and anadromous fishes. Journal of Fish Biology 44: $213-232$.

Wedekind, C. \& Muller, R. 2004. The experimental rearing of large salmonid eggs in Petri dishes. Functional Ecology 18: 138-140.

Wilson, A.J., Gislason, D., Skulason, S., Snorrason, S.S., Adams, C.E., Alexander, G., Danzmann, R.G. \& Ferguson, M.M. 2004. Population genetic structure of Arctic Charr, Salvelinus alpinus from northwest Europe on large and small spatial scales. Molecular Ecology 13: 1129-1142.

Yeaman, S. \& Otto, S.P. 2011. Establishment and maintenance of adaptive genetic divergence under migration, selection, and drift. Evolution 65: 2123-2129.

\section{Acknowledgements}

The authors thank Shenglin Liu, Rasmus Hedeholm, Lars Heilman, Anne-Laure Ferchaud and Nynne Hjort Nielsen for assistance with collecting samples, two 
ananymous reviewers for comments and suggestions and The Danish Council for Independent Research, Natural Science for funding (grant no. 1323-00158A to Michael M. Hansen).

\section{Authors' Contribution Statement}

Conceived and designed the investigation: MMH, RPAM, MWJ, LB, DJF, RN, KGO. Performed field and/or laboratory work: RPAM, MWJ, MMH, LB, DJF, KP, RN, BJ, JMP. Analyzed the data: RPAM, MMH, MWJ. Contributed materials, reagents, and/or analysis tools: MMH. Wrote the paper: RPAM, MMH, MWJ with contributions from LB, DJF, KP, KGO, RN, BJ, JMP.

\section{Figure legends}

Fig. 1. Map showing the approximate location of the sampled localities. See Table 1 for geographical coordinates.

Fig. 2. Results of DAPC analysis (Jombart et al. 2010) based on SNPs for analyzing genetic relationships between the sampled Arctic char. a) Number of individuals from each sample assigned to the nine inferred groups. b) Scatterplot of individuals along the two first discriminant functions and with a minimum spanning tree superimposed. The inserted barplot shows the eigenvalues of the analysis.

Fig. 3. Analysis of isolation-by-distance involving the Western Greenland anadromous populations. Shaded areas denote $95 \%$ confidence intervals of the fitted lines. a) Isolation-by-distance based on SNPs $\left(\mathrm{R}^{2}=0.92, \mathrm{p}<0.0001\right)$. b) Isolation-by-distance based on phenology-related loci $\left(\mathrm{R}^{2}=0.55, \mathrm{p}<0.0001\right)$.

Fig. 4. Results of spatial autocorrelation analysis based on individual-based genetic distance and geographical distance, implemented in GenAlEx 6.5 (Peakall and Smouse 2006, 2012; Smouse and Peakall 1999). The results show the geographical scale in Western Greenland over which individual genotypes show non-random association, as determined by the first intercept with the $\mathrm{x}$-axis. The shaded areas around the line denotes the $95 \%$ confidence interval of $r$ values, and the shaded area along the $\mathrm{x}$-axis denotes the $95 \%$ confidence interval in case of no spatial structure of individuals, both determined by bootstrapping over individuals.

Fig. 5. SST (sea surface temperature) windows close to the river mouths of the sampled populations, defined as the time periods during the year when SST exceeded $2^{\circ} \mathrm{C}$ based on mean SST of the years 1984, 1994, 2004 and 2014 . The beginning of the SST window is defined as the first date of the year when SST exceeds $2^{\circ} \mathrm{C}$ (marked by the red dashed line) and the end of the SST window is defined as the date of the year when SST again drops below $2^{\circ} \mathrm{C}$. Figs. 5.a-m shows SST windows for all the sampled anadromous populations. The mouths of the rivers inhabited by populations NUUK-2, 
842 NUUK-3, NUUK-4 and NUUK-5 are geographically close, and these populations 843 therefore share the same SST window (Fig. 4.j).

844

845

846

847 
Table 1. Overview of samples and localities showing sample codes, localities, geographical coordinates, major geographic regions, year of sampling, life history of populations, sample size $(\mathrm{N})$ and mean expected heterozygosity $\left(\mathrm{H}_{\mathrm{e}}\right)$ for SNPs and phenology-related markers, respectively.

\begin{tabular}{|c|c|c|c|c|c|c|c|c|c|}
\hline $\begin{array}{l}\text { Sample } \\
\text { code }\end{array}$ & Locality & Latitude & Longitude & $\begin{array}{l}\text { Major geographic } \\
\text { region }\end{array}$ & $\begin{array}{l}\text { Year of } \\
\text { sampling }\end{array}$ & $\begin{array}{l}\text { Life history } \\
\text { form }\end{array}$ & $\mathrm{N}$ & $\begin{array}{l}\mathrm{H}_{\mathrm{e}} \\
\text { (SNPs) }\end{array}$ & $\begin{array}{l}\mathrm{H}_{\mathrm{e}} \text { (phenology- } \\
\text { related) }\end{array}$ \\
\hline QAAN-1 & Qaanaaq & $77.46^{\circ} \mathrm{N}$ & $-69.23 W$ & Western Greenland & 2012 & Anadromous & 18 & 0.11 & 0.18 \\
\hline UUMM-1 & Umivik & $71.66^{\circ} \mathrm{N}$ & $-54.10 W$ & Western Greenland & 2015 & Anadromous & 20 & 0.29 & 0.35 \\
\hline UUMM-2 & Sermeerlat & $70.54^{\circ} \mathrm{N}$ & $-50.77 W$ & Western Greenland & 2015 & Anadromous & 20 & 0.26 & 0.27 \\
\hline DISK-1 & Disko Island & $69.25^{\circ} \mathrm{N}$ & $-53.51 W$ & Western Greenland & 2014 & Anadromous & 20 & 0.28 & 0.40 \\
\hline KANG-1 & Robinson River & $66.71^{\circ} \mathrm{N}$ & $-51.43 W$ & Western Greenland & 2014 & Anadromous & 20 & 0.22 & 0.59 \\
\hline SISI-1 & Sisimiut & $66.43^{\circ} \mathrm{N}$ & $-53.61 W$ & Western Greenland & 2014 & Anadromous & 20 & 0.32 & 0.51 \\
\hline MANI-1 & Kangerdluarssuk & $65.57 \mathrm{~N}^{\circ}$ & $-52.38 W$ & Western Greenland & 2014 & Anadromous & 20 & 0.30 & 0.58 \\
\hline MANI-2 & Kangia & $65.31^{\circ} \mathrm{N}$ & $-51.97 W$ & Western Greenland & 2015 & Anadromous & 20 & 0.26 & 0.65 \\
\hline NUUK-1 & Kapisilit & $64.42^{\circ} \mathrm{N}$ & $-50.20 W$ & Western Greenland & 2012 & Anadromous & 18 & 0.22 & 0.47 \\
\hline NUUK-2 & Kobbefjord & $64.14^{\circ} \mathrm{N}$ & $-51.38 W$ & Western Greenland & 2013 & Anadromous & 19 & 0.27 & 0.55 \\
\hline NUUK-3 & Præstefjord & $64.00^{\circ} \mathrm{N}$ & $-51.24 W$ & Western Greenland & 2013 & Anadromous & 20 & 0.28 & 0.50 \\
\hline NUUK-4 & Qarajat & $63.99^{\circ} \mathrm{N}$ & $-51.45 W$ & Western Greenland & 2012 & Anadromous & 20 & 0.25 & 0.51 \\
\hline NUUK-5 & Eqaluit & $64.13^{\circ} \mathrm{N}$ & $-50.47 W$ & Western Greenland & 2012 & Anadromous & 20 & 0.30 & 0.63 \\
\hline QAQO-1 & Lakseelv & $60.89^{\circ} \mathrm{N}$ & $-45.84 W$ & Western Greenland & 2014 & Anadromous & 20 & 0.16 & 0.34 \\
\hline QAQO-2 & Eqaluit & $60.76^{\circ} \mathrm{N}$ & $-45.54 \mathrm{~W}$ & Western Greenland & 2014 & Anadromous & 20 & 0.15 & 0.41 \\
\hline SCOR-1 & Scoresbysund & $70.35^{\circ} \mathrm{N}$ & $-28.14 W$ & Eastern Greenland & 2012 & Anadromous & 20 & 0.08 & 0.26 \\
\hline ICEL-1 & Vatnshlidarvatn & $65.52^{\circ} \mathrm{N}$ & $-19.64 W$ & Iceland & 2016 & Landlocked & 20 & 0.07 & 0.59 \\
\hline NORW-1 & Biggijavri & $69.33^{\circ} \mathrm{N}$ & $23.45 \mathrm{~W}$ & Norway & 2005 & Landlocked & 16 & 0.06 & 0.34 \\
\hline
\end{tabular}


Table 2. Tests for association between mean allele length at OtsClock1b and latitude or sea surface temperature parameters at different geographical scales. Significant results are highlighted in bold.

\begin{tabular}{|c|c|c|}
\hline Parameter tested & Geographical scale & Result \\
\hline Latitude & All populations & $\begin{array}{l}y=1.44 x+308.02, R_{\text {adjusted }}^{2}=0.08 \\
p=0.129\end{array}$ \\
\hline Latitude & $\begin{array}{l}\text { Anadromous populations, } \\
\text { Eastern and Western } \\
\text { Greenland }\end{array}$ & $\begin{array}{l}y=1.38 x+311.32, R^{2}{ }_{\text {adjusted }}=0.06 \\
p=0.175\end{array}$ \\
\hline Latitude & $\begin{array}{l}\text { Anadromous populations, } \\
\text { Western Greenland }\end{array}$ & $\begin{array}{l}y=1.62 x+296.84, R^{2} \text { adjusted }=0.11 \\
p=0.128\end{array}$ \\
\hline SST-window start date & $\begin{array}{l}\text { Anadromous populations, } \\
\text { Eastern and Western } \\
\text { Greenland }\end{array}$ & $\begin{array}{l}y=0.29 x+359.18, R^{2}{ }_{\text {adjusted }}=0.17 \\
p=0.062\end{array}$ \\
\hline SST-window start date & $\begin{array}{l}\text { Anadromous populations, } \\
\text { Western Greenland }\end{array}$ & $\begin{array}{l}y=0.46 x+334.82, R^{2}{ }_{\text {adjusted }}=0.39 \\
p=0.007\end{array}$ \\
\hline SST-window end date & $\begin{array}{l}\text { Anadromous populations, } \\
\text { Eastern and Western } \\
\text { Greenland }\end{array}$ & $\begin{array}{l}y=-0.20 x+459.81, R^{2} \text { adjusted }= \\
-0.01, p=0.365\end{array}$ \\
\hline SST-window end date & $\begin{array}{l}\text { Anadromous populations, } \\
\text { Western Greenland }\end{array}$ & $\begin{array}{l}y=-0.27 x+483.70, R^{2}{ }_{\text {adjusted }}= \\
0.04, p=0.238\end{array}$ \\
\hline SST-window duration & $\begin{array}{l}\text { Anadromous populations, } \\
\text { Eastern and Western } \\
\text { Greenland }\end{array}$ & $\begin{array}{l}y=-0.17 x+425.95, R^{2}{ }_{\text {adjusted }}= \\
0.12, p=0.100\end{array}$ \\
\hline SST-window duration & $\begin{array}{l}\text { Anadromous populations, } \\
\text { Western Greenland }\end{array}$ & $\begin{array}{l}y=-0.267 x+441.42, R_{\text {adjusted }}= \\
0.308, p=0.019\end{array}$ \\
\hline
\end{tabular}




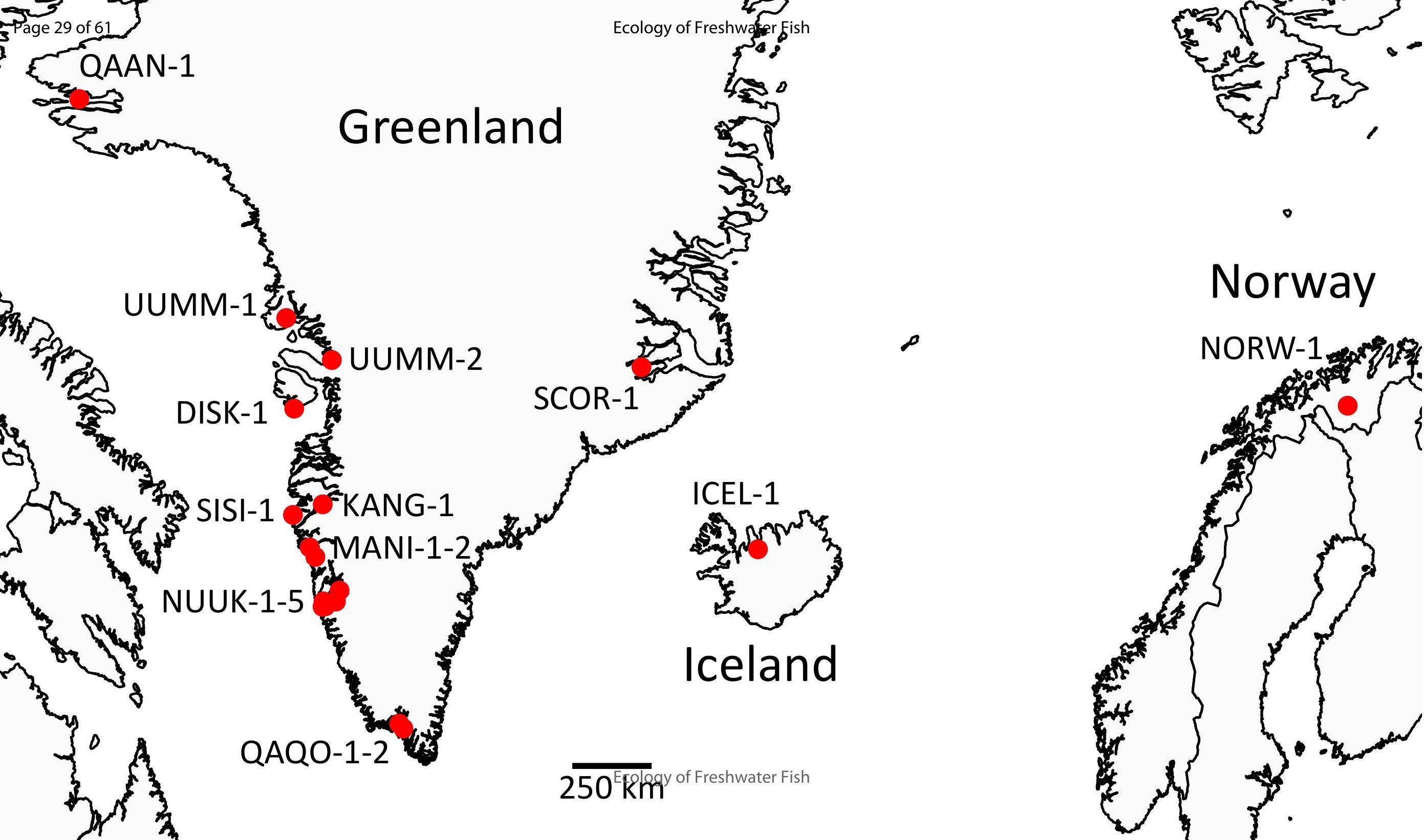


a)

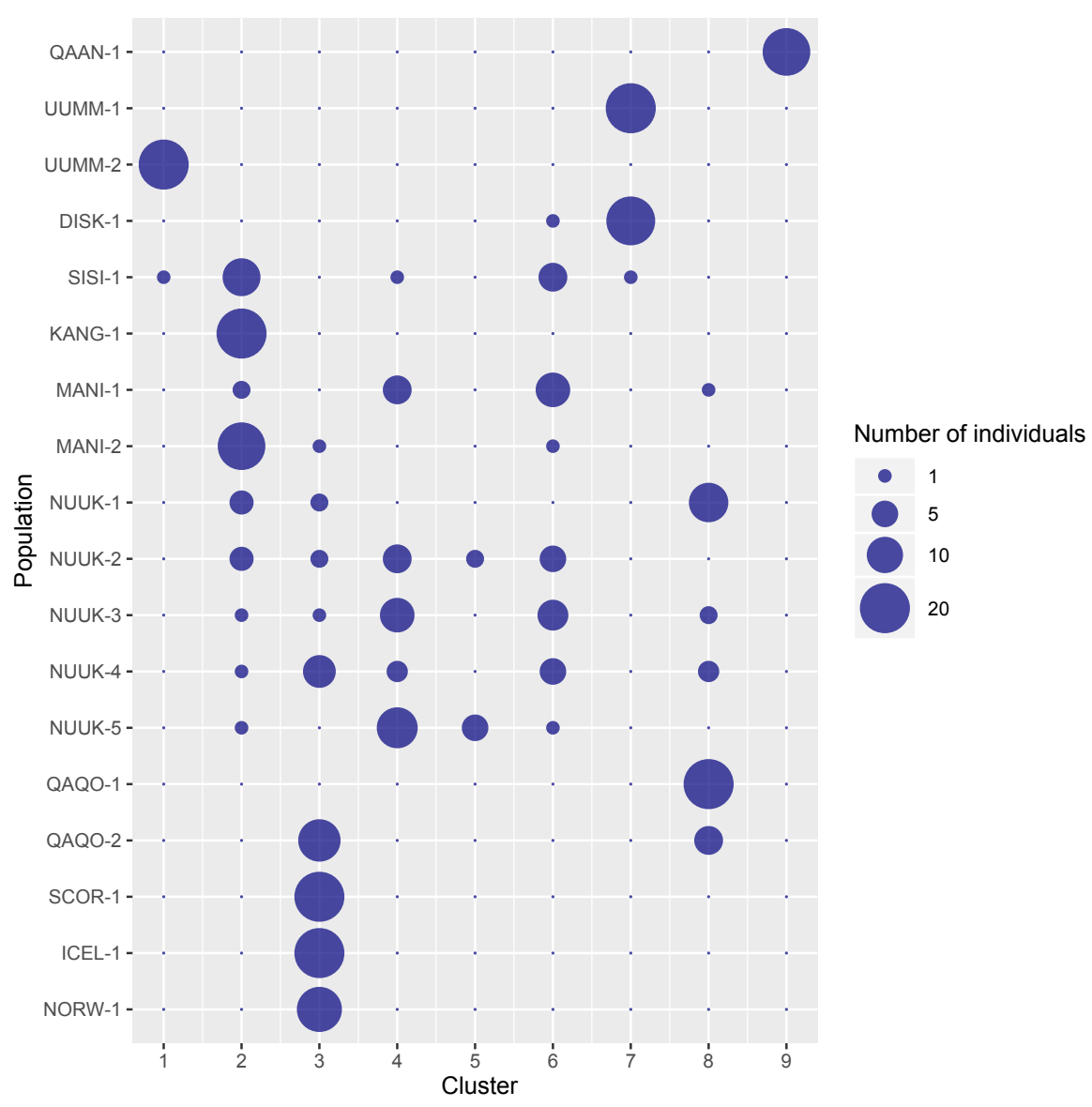

b)

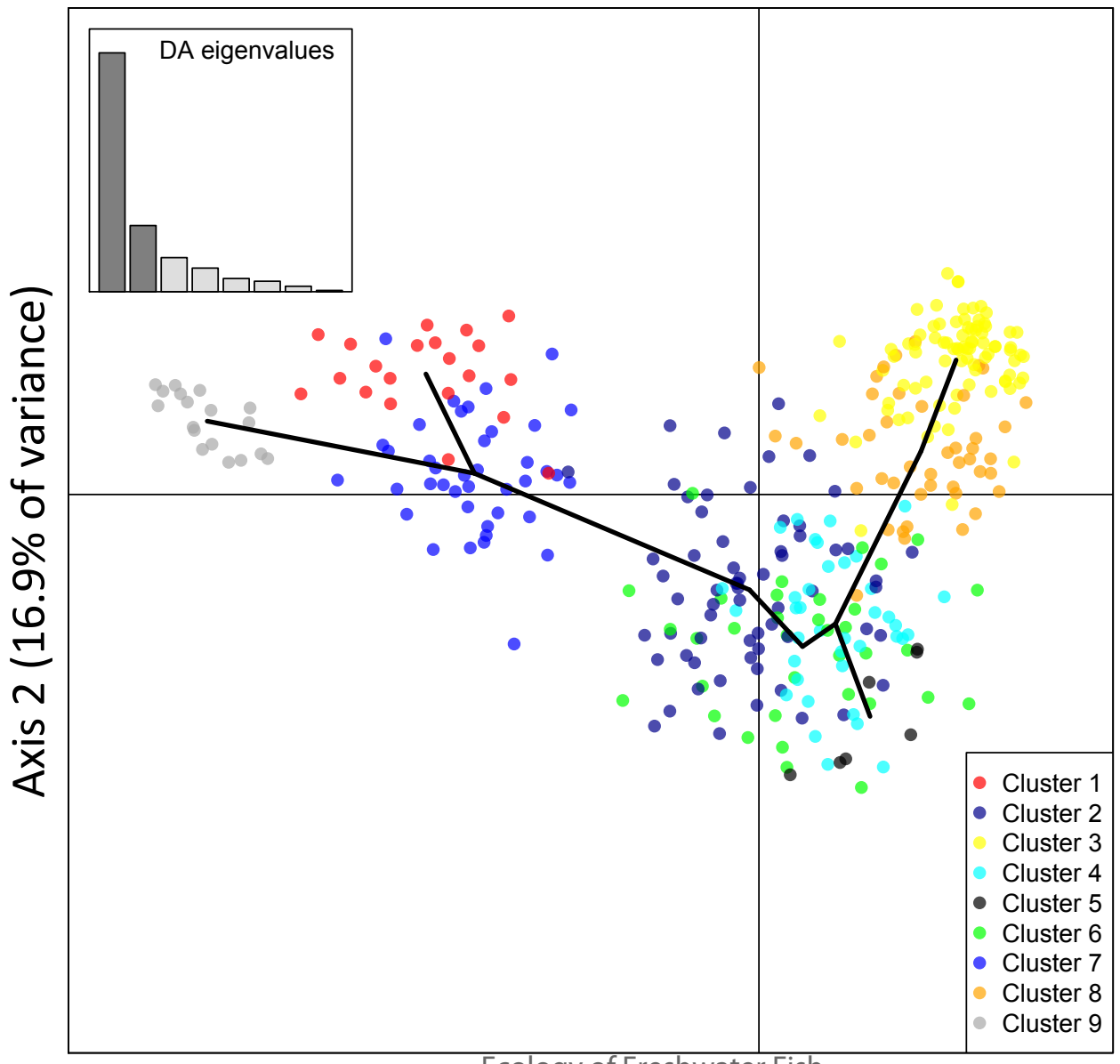




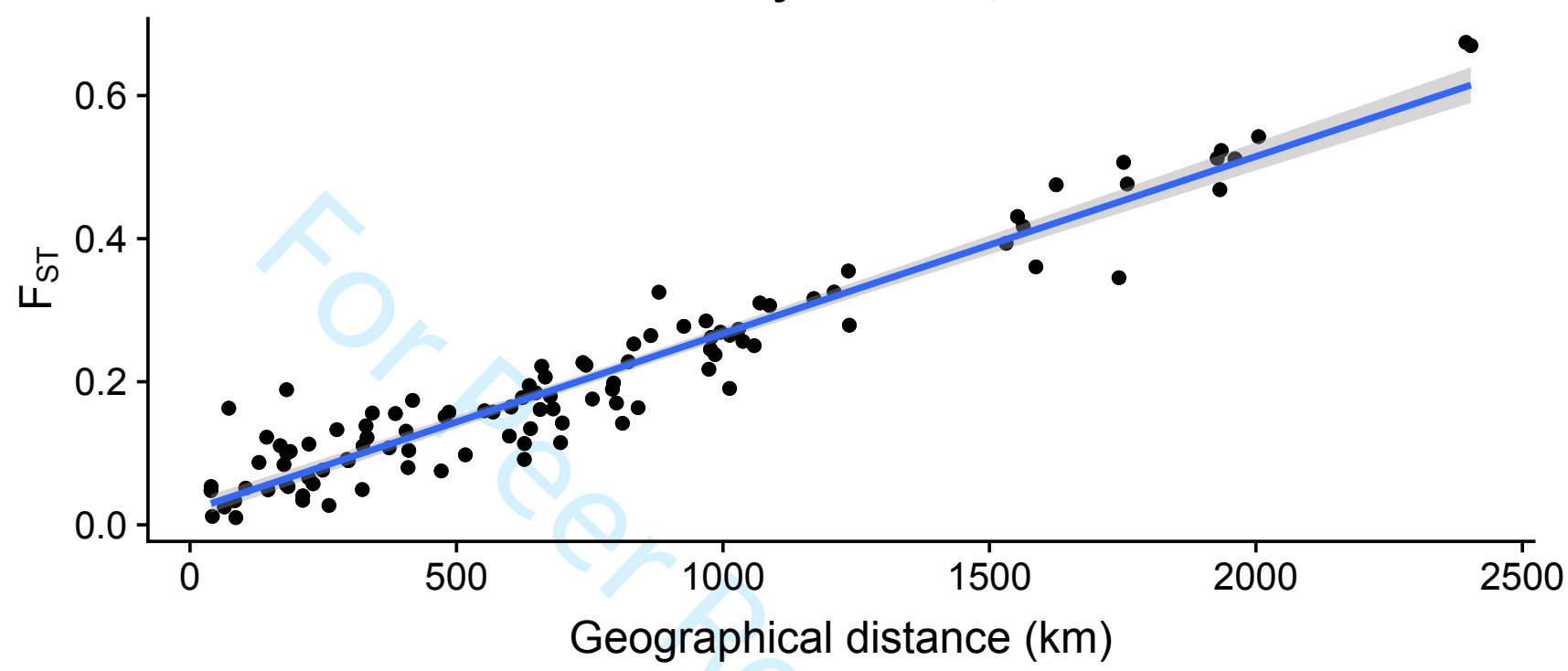

b)

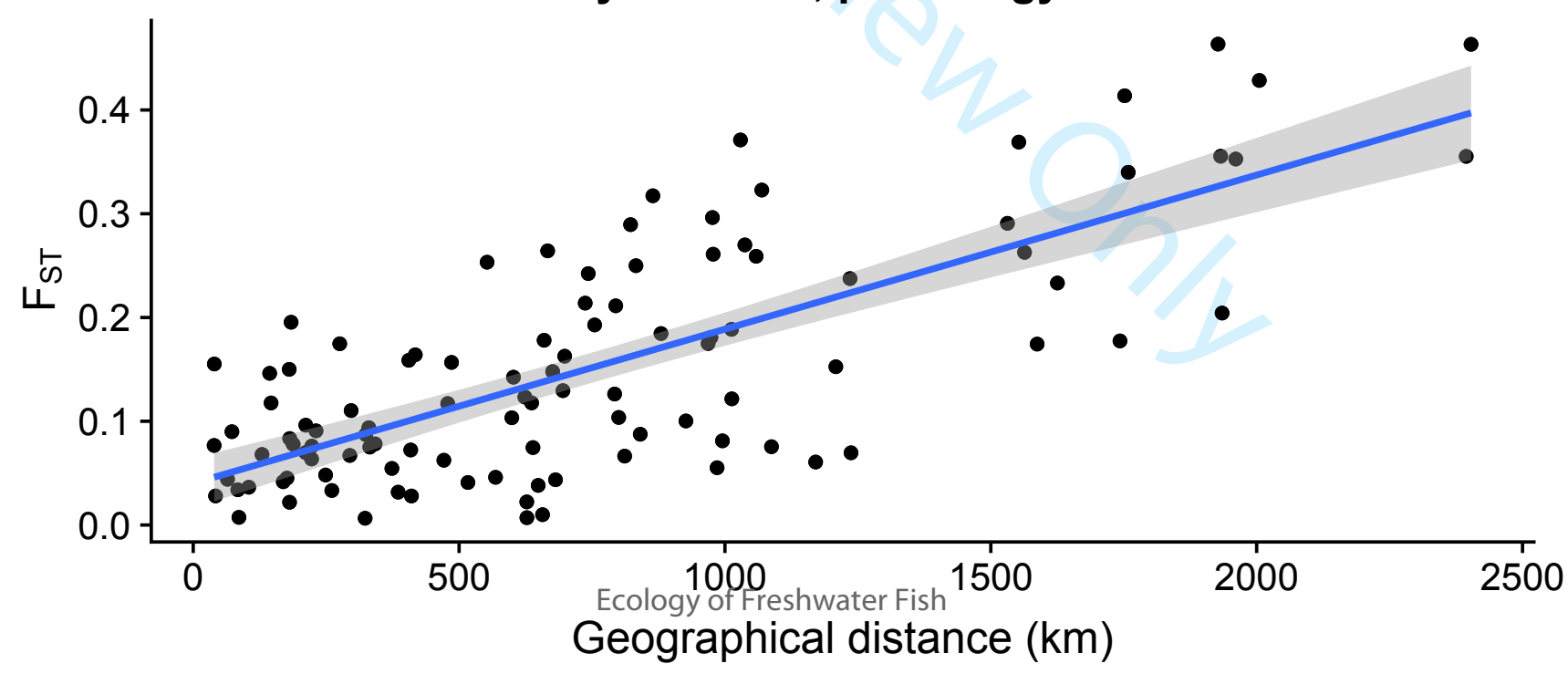

Isolation by distance, phenology-related loci

Geographical distance (km) 
Supporting Information for

Genetic population structure and variation at phenologyrelated loci in anadromous Arctic char (Salvelinus alpinus) 
Table S1. Genotypes at the three phenology-related loci Cryptochrome2.b.2, Cryptochrome3, Ots515NWFSC and OtsClock1b of parents and offspring in experimental crosses of Arctic char.

\begin{tabular}{|c|c|c|c|c|c|c|}
\hline & \multicolumn{3}{|c|}{ Family 1} & \multicolumn{3}{|c|}{ Family 2} \\
\hline Locus & Male & Female & Offspring & Male & Female & Offspring \\
\hline Cryptochrome2.b.2 & $258 / 258$ & $258 / 258$ & $258 / 258(10)$ & $258 / 258$ & $258 / 258$ & $258 / 258(10)$ \\
\hline Cryptochrome3 & $357 / 357$ & $357 / 357$ & $357 / 357(10)$ & $357 / 359$ & $357 / 357$ & $\begin{array}{l}357 / 357(5) \\
357 / 359(5)\end{array}$ \\
\hline Ots515NWFSC & $258 / 268$ & $272 / 293$ & $\begin{array}{l}268 / 293(2) \\
258 / 272(3) \\
258 / 293(3) \\
268 / 272(2)\end{array}$ & $272 / 303$ & $262 / 272$ & $\begin{array}{l}262 / 303(4) \\
262 / 272(2) \\
272 / 303(1) \\
272 / 272(3)\end{array}$ \\
\hline OtsClock1b & $426 / 426$ & $426 / 426$ & $426 / 426(10)$ & $391 / 426$ & $337 / 426$ & $\begin{array}{l}337 / 391(3) \\
337 / 426(3) \\
391 / 426(2) \\
426 / 426(2)\end{array}$ \\
\hline
\end{tabular}


Table S3. FST between all pairs of samples. Above diagonal: $F_{S T}$ at phenology-related loci. Below diagonal: $F_{S T}$ at SNPs. Non-significant values are denoted by green.

\begin{tabular}{|c|c|c|c|c|c|c|c|c|c|c|c|c|c|c|c|c|c|c|}
\hline & QAAN-1 & UUMM-1 & 1 UUMM-2 & DISK-1 & SISI-1 & KANG-1 & MANI-1 & MANI-2 & NUUK-1 & NUUK-2 & NUUK-3 & NUUK-4 & NUUK-5 & QAQO-1 & QAQO-2 & SCOR-1 & ICEL-1 & NORW-1 \\
\hline QAAN-1 & 0.00 & $0.05^{*}$ & 0.04 & $0.05^{*}$ & $0.10^{* * *}$ & $0.14^{* * *}$ & $0.20^{* * *}$ & $0.27^{* * *}$ & $0.29^{* * *}$ & $0.23^{* * *}$ & $0.22^{* * *}$ & $0.13^{* * *}$ & $0.31^{* * *}$ & $0.31^{* * *}$ & $0.22^{* * *}$ & $0.47^{* * *}$ & $0.37^{* * *}$ & $0.33^{* * *}$ \\
\hline UUMM-1 & $0.19^{* * *}$ & 0.00 & 0.02 & 0.02 & $0.05^{*}$ & $0.08^{* * *}$ & $0.13^{* * *}$ & $0.19^{* * *}$ & $0.18^{* * *}$ & $0.12^{* * *}$ & $0.12^{* * *}$ & $0.04^{*}$ & $0.19^{* * *}$ & $0.19^{* * *}$ & $0.10^{* * *}$ & $0.33^{* * *}$ & $0.26^{* * *}$ & $0.23^{* * *}$ \\
\hline UUMM-2 & $0.20^{* * *}$ & $0.11^{* * *}$ & 0.00 & 0.03 & 0.06 & $0.11^{* * *}$ & $0.15^{* * *}$ & $0.21^{* * *}$ & $0.21^{* * *}$ & $0.17^{* * *}$ & $0.16^{* * *}$ & $0.08^{* * *}$ & $0.24^{* * *}$ & $0.24^{* * *}$ & $0.16^{* * *}$ & $0.38^{* * *}$ & $0.30^{* * *}$ & $0.25^{* * *}$ \\
\hline DISK-1 & $0.17^{* * *}$ & $0.04^{* * *}$ & $0.10^{* * *}$ & 0.00 & $0.03^{*}$ & $0.06^{* *}$ & $0.09^{* * *}$ & $0.16^{* * *}$ & $0.13^{* * *}$ & $0.09^{* * *}$ & $0.10^{* * *}$ & $0.03^{*}$ & $0.16^{* * *}$ & $0.15^{* * *}$ & $0.09^{* * *}$ & $0.28^{* * *}$ & $0.22^{* * *}$ & $0.20^{* * *}$ \\
\hline SISI-1 & $0.21^{* * *}$ & $0.09^{* * *}$ & $0.10^{* * *}$ & $0.06^{* * *}$ & 0.00 & $0.03^{*}$ & $0.03^{*}$ & $0.07^{*}$ & $0.08^{* * *}$ & $0.05^{*}$ & $0.04^{*}$ & 0.02 & $0.10^{* * *}$ & $0.11^{* * *}$ & $0.05^{*}$ & $0.19^{* * *}$ & $0.19^{* * *}$ & $0.15^{* * *}$ \\
\hline KANG-1 & $0.32^{* * *}$ & $0.12^{* * *}$ & $0.14^{* * *}$ & $0.09^{* * *}$ & $0.05^{* * *}$ & 0.00 & 0.04 & $0.05^{* * *}$ & $0.10^{* * *}$ & $0.06^{* * *}$ & $0.04^{*}$ & $0.05^{* * *}$ & $0.05^{* *}$ & $0.11^{* * *}$ & $0.07^{* *}$ & $0.22^{* * *}$ & $0.13^{* * *}$ & $0.18^{* * *}$ \\
\hline MANI-1 & $0.32^{* * *}$ & $0.12^{* * *}$ & $0.16^{* * *}$ & $0.10^{* * *}$ & $0.05^{* * *}$ & $0.07^{* * *}$ & 0.00 & $0.03^{*}$ & $0.04^{* * *}$ & $0.04^{* *}$ & 0.03 & $0.06^{* * *}$ & $0.05^{* *}$ & $0.07^{* * *}$ & $0.06^{* * *}$ & $0.14^{* * *}$ & $0.14^{* * *}$ & $0.17^{* * *}$ \\
\hline MANI-2 & $0.35^{* * *}$ & $0.14^{* * *}$ & $0.17^{* * *}$ & $0.10^{* * *}$ & $0.06^{* * *}$ & $0.07^{* * *}$ & $0.04^{* * *}$ & 0.00 & $0.11^{* * *}$ & $0.09^{* * *}$ & $0.06^{* * *}$ & $0.12^{* * *}$ & $0.05^{* * *}$ & $0.15^{* * *}$ & $0.12^{* * *}$ & $0.22^{* * *}$ & $0.18^{* * *}$ & $0.23^{* * *}$ \\
\hline NUUK-1 & $0.38^{* * *}$ & $0.16^{* * *}$ & $0.20^{* * *}$ & $0.14^{* * *}$ & $0.09^{* * *}$ & $0.11^{* * *}$ & $0.06^{* * *}$ & $0.09^{* * *}$ & 0.00 & $0.05^{* *}$ & $0.05^{* * *}$ & $0.08^{* * *}$ & $0.09^{* * *}$ & 0.04 & $0.09^{* * *}$ & $0.11^{* * *}$ & $0.21^{* * *}$ & $0.21^{* * *}$ \\
\hline NUUK-2 & $0.36^{* * *}$ & $0.13^{* * *}$ & $0.16^{* * *}$ & $0.11^{* * *}$ & $0.05^{* * *}$ & $0.07^{* * *}$ & $0.03^{* * *}$ & $0.04^{* * *}$ & $0.06^{* * *}$ & 0.00 & 0.02 & 0.03 & $0.05^{* * *}$ & $0.04^{*}$ & 0.02 & $0.14^{* * *}$ & $0.18^{* * *}$ & $0.17^{* * *}$ \\
\hline NUUK-3 & $0.32^{* * *}$ & $0.12^{* * *}$ & $0.16^{* * *}$ & $0.09^{* * *}$ & $0.05^{* * *}$ & $0.07^{* * *}$ & $0.03^{* *}$ & $0.04^{* * *}$ & $0.07^{* * *}$ & 0.02 & 0.00 & $0.03^{*}$ & $0.03^{*}$ & $0.05^{* *}$ & 0.02 & $0.18^{* * *}$ & $0.19^{* * *}$ & $0.18^{* * *}$ \\
\hline NUUK-4 & $0.36^{* * *}$ & $0.14^{* * *}$ & $0.16^{* * *}$ & $0.11^{* * *}$ & $0.06^{* * *}$ & $0.08^{* * *}$ & $0.03^{* *}$ & $0.04^{* * *}$ & $0.04^{* * *}$ & 0.02 & $0.03^{* *}$ & 0.00 & $0.09^{* * *}$ & $0.07^{* * *}$ & 0.02 & $0.21^{* * *}$ & $0.20^{* * *}$ & $0.17^{* * *}$ \\
\hline NUUK-5 & $0.36^{* * *}$ & $0.15^{* * *}$ & $0.17^{* * *}$ & $0.13^{* * *}$ & $0.08^{* * *}$ & $0.10^{* * *}$ & $0.05^{* * *}$ & $0.07^{* * *}$ & $0.08^{* * *}$ & $0.04^{* * *}$ & $0.03^{* * *}$ & $0.04^{* * *}$ & 0.00 & $0.09^{* * *}$ & $0.08^{* * *}$ & $0.20^{* * *}$ & $0.16^{* * *}$ & $0.23^{* * *}$ \\
\hline QAQO-1 & $0.51^{* * *}$ & $0.25^{* * *}$ & $0.29^{* * *}$ & $0.23^{* * *}$ & $0.17^{* * *}$ & $0.21^{* * *}$ & $0.12^{* * *}$ & $0.14^{* * *}$ & $0.10^{* * *}$ & $0.10^{* * *}$ & $0.09^{* * *}$ & $0.08^{* * *}$ & $0.10^{* * *}$ & 0.00 & 0.06 & $0.15^{* * *}$ & $0.22^{* * *}$ & $0.22^{* * *}$ \\
\hline QAQO-2 & $0.52^{* * *}$ & $0.23^{* * *}$ & $0.27^{* * *}$ & $0.21^{* * *}$ & $0.16^{* * *}$ & $0.17^{* * *}$ & $0.10^{* * *}$ & $0.11^{* * *}$ & $0.07^{* * *}$ & $0.07^{* * *}$ & $0.10^{* * *}$ & $0.06^{* * *}$ & $0.11^{* * *}$ & $0.10^{* * *}$ & 0.00 & $0.20^{* * *}$ & $0.23^{* * *}$ & $0.18^{* * *}$ \\
\hline SCOR-1 & $0.63^{* * *}$ & $0.31^{* * *}$ & $0.33^{* * *}$ & $0.27^{* * *}$ & $0.22^{* * *}$ & $0.21^{* * *}$ & $0.15^{* * *}$ & $0.15^{* * *}$ & $0.15^{* * *}$ & $0.12^{* * *}$ & $0.14^{* * *}$ & $0.09^{* * *}$ & $0.17^{* * *}$ & $0.18^{* * *}$ & $0.12^{* * *}$ & 0.00 & $0.23^{* * *}$ & $0.26^{* * *}$ \\
\hline ICEL-1 & $0.66^{* * *}$ & $0.34^{* * *}$ & $0.36^{* * *}$ & $0.32^{* * *}$ & $0.26^{* * *}$ & $0.29^{* * *}$ & $0.19^{* * *}$ & $0.21^{* * *}$ & $0.18^{* * *}$ & $0.16^{* * *}$ & $0.18^{* * *}$ & $0.12^{* * *}$ & $0.20^{* * *}$ & $0.17^{* * *}$ & $0.15^{* * *}$ & $0.15^{* * *}$ & 0.00 & $0.23^{* * *}$ \\
\hline NORW-1 & $0.67^{* * *}$ & $0.31^{* * *}$ & $0.36^{* * *}$ & $0.29^{* * *}$ & $0.24^{* * *}$ & $0.23^{* * *}$ & $0.16^{* * *}$ & $0.17^{* * *}$ & $0.16^{* * *}$ & $0.13^{* * *}$ & $0.16^{* * *}$ & $0.11^{* * *}$ & $0.17^{* * *}$ & $0.21^{* * *}$ & $0.10^{* * *}$ & $0.09^{* * *}$ & $0.26^{* * *}$ & 0.00 \\
\hline
\end{tabular}

${ }^{* * *} \mathrm{p}<0.001,{ }^{* *} \mathrm{p}<0.01,{ }^{*} \mathrm{p}<0.05$ after False Discovery Rate correction (B-Y method, Narum (2006))

Narum, S.R. 2006. Beyond Bonferroni: Less conservative analyses for conservation genetics. Conservation Genetics 7: $783-787$. 
Table S4. Mean allele length at OtsClock1b along with latitude, start and end day of SST window.

\begin{tabular}{llllll}
\hline Population & $\begin{array}{l}\text { Mean allele } \\
\text { length at } \\
\text { OtsClock1b }\end{array}$ & $\begin{array}{l}\text { Allele } \\
\text { length } \\
\text { s.d. }\end{array}$ & Latitude & $\begin{array}{l}\text { Start of SST } \\
\text { window (day of } \\
\text { year) }\end{array}$ & $\begin{array}{l}\text { End of SST } \\
\text { window (day of } \\
\text { year) }\end{array}$ \\
\hline QAAN-1 & 426.00 & 0.00 & 77.47 & 187 & 245 \\
UUMM-1 & 424.16 & 7.92 & 71.66 & 180 & 263 \\
UUMM-2 & 416.45 & 25.92 & 70.54 & 201 & 260 \\
DISK-1 & 418.88 & 16.75 & 69.25 & 147 & 293 \\
KANG-1 & 398.25 & 39.91 & 66.43 & 131 & 297 \\
SISI-1 & 398.80 & 35.13 & 66.71 & 134 & 295 \\
MANI-1 & 387.93 & 36.86 & 65.57 & 133 & 292 \\
MANI-2 & 363.88 & 39.79 & 65.31 & 132 & 293 \\
NUUK-1 & 388.19 & 33.57 & 64.42 & 133 & 294 \\
NUUK-2 & 406.24 & 31.48 & 64.14 & 134 & 294 \\
NUUK-3 & 400.60 & 37.90 & 64.29 & 134 & 294 \\
NUUK-4 & 418.88 & 37.90 & 64 & 134 & 294 \\
NUUK-5 & 389.39 & 42.89 & 63.99 & 134 & 294 \\
QAQO-1 & 408.83 & 26.15 & 60.89 & 171 & 321 \\
QAQO-2 & 417.63 & 22.11 & 60.76 & 176 & 321 \\
SCOR-1 & 393.26 & 14.55 & 70.35 & 208 & 261 \\
ICEL-1 & 405.00 & 17.36 & 65.52 & NA & NA \\
NORW-1 & 415.06 & 16.48 & 69.33 & NA & NA \\
\hline
\end{tabular}


Fig. S1. Bayesian Information Criterion values assuming $\mathrm{k}$ from 1 to 40 clusters based on individuals in the SNP data set. The lowest BIC value was obtained for $k=9$.

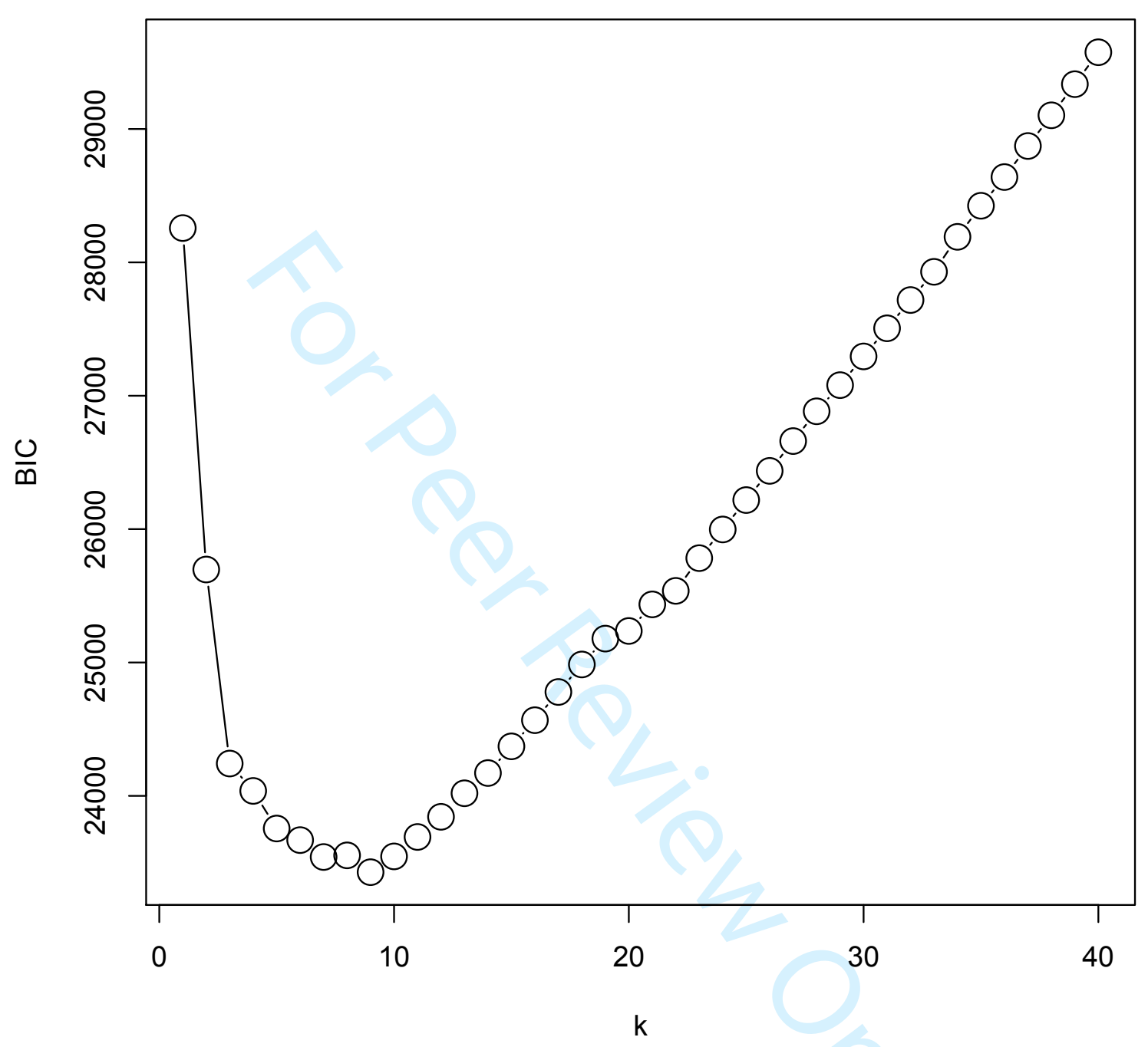


Fig. S2a. Results of $F_{S T}$-based outlier test (Beaumont \& Nichols, 1996) involving all populations.

\section{Detection of loci under selection from genome scans based on $\mathrm{F}_{\mathrm{ST}}$}

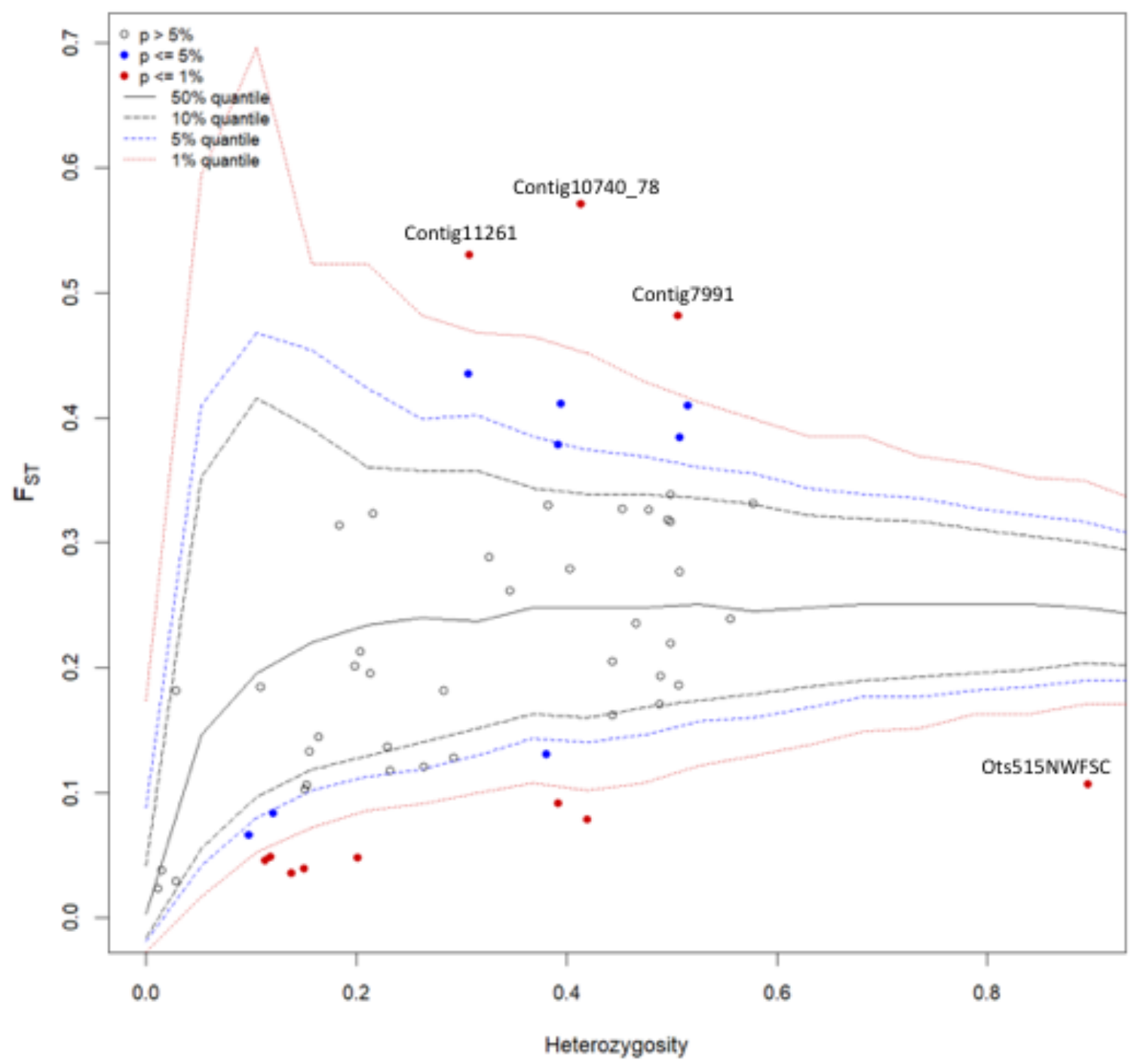


Fig. S2b. Results of hierarchical outlier test (Excoffier et al. 2009) involving Western Greenland populations (excluding QAAN-1).

Detection of loci under selection from genome scans based on $\mathrm{F}_{\mathrm{ST}}$

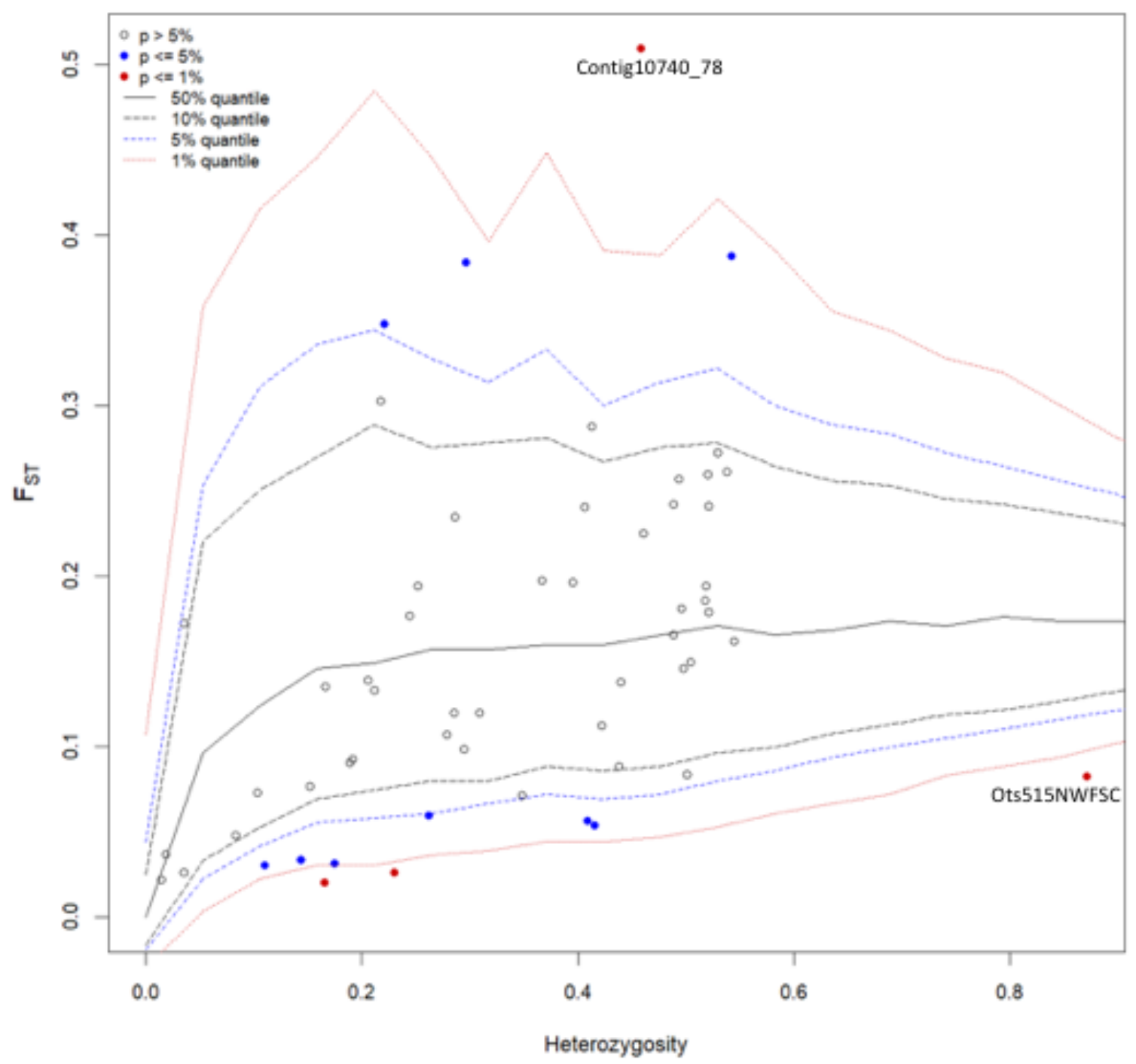


Fig. S3. Plots of association between mean allele length at OtsClock $1 b$ and geographical and environmental parameters for the sampled populations. Shaded areas denote $95 \%$ confidence intervals of the fitted lines. a) Mean allele length and latitude, encompassing all populations ( $y=1.44 x+308.02, R^{2}$ adjusted $\left.=0.08, p=0.129\right)$.

b) Mean allele length and start day of SST (sea surface temperature) window, encompassing all anadromous populations $\left(y=0.29 x+359.18, R^{2}\right.$ adjusted $=0.173, p=$ 0.0615). c) Mean allele length and end day of SST window, encompassing all anadromous populations ( $y=-0.20 x+459.81, R^{2}$ adjusted $\left.=-0.01, p=0.365\right)$. d) Mean allele length and duration of SST window, encompassing all anadromous populations $\left(y=-0.167 x+425.95, R^{2}\right.$ adjusted $\left.=0.12, p=0.10\right)$. e) Mean allele length and start day of SST window, encompassing all anadromous populations from Western Greenland $(y=$ $0.46 x+334.82, R^{2}$ adjusted $\left.=0.39, p=0.007\right) . f$ ) Mean allele length and duration of SST window, encompassing all anadromous populations from Western Greenland ( $y=-$ $\left.0.267 x+441.42, R^{2}{ }_{\text {adjusted }}=0.308, p=0.019\right)$.

a)

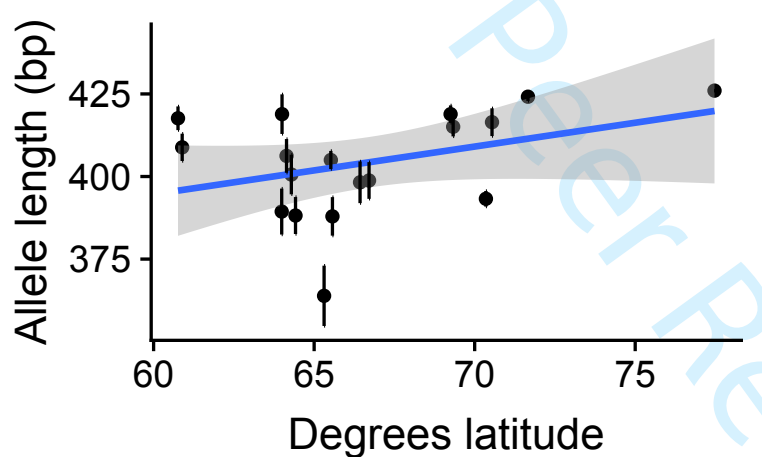

c)

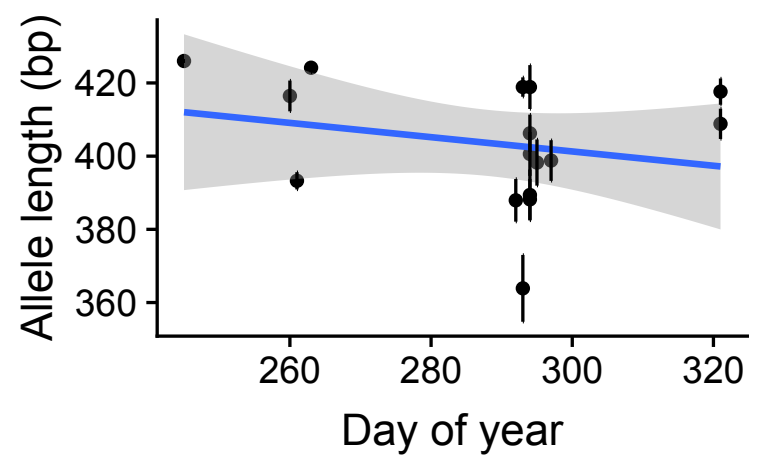

e)

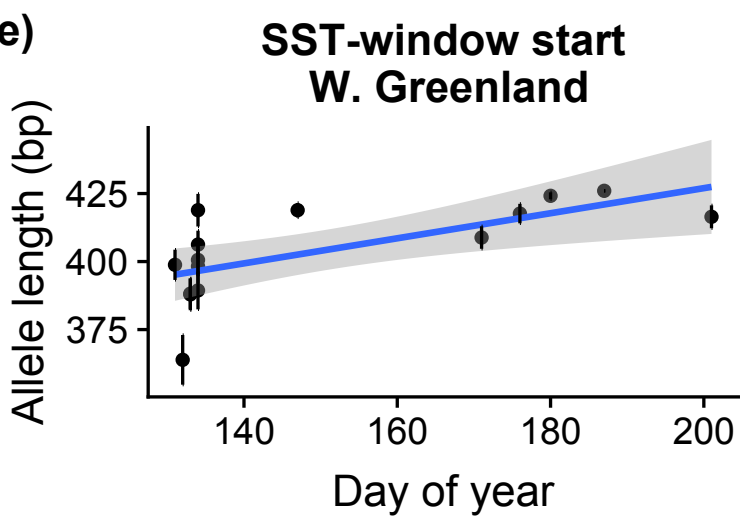

b)

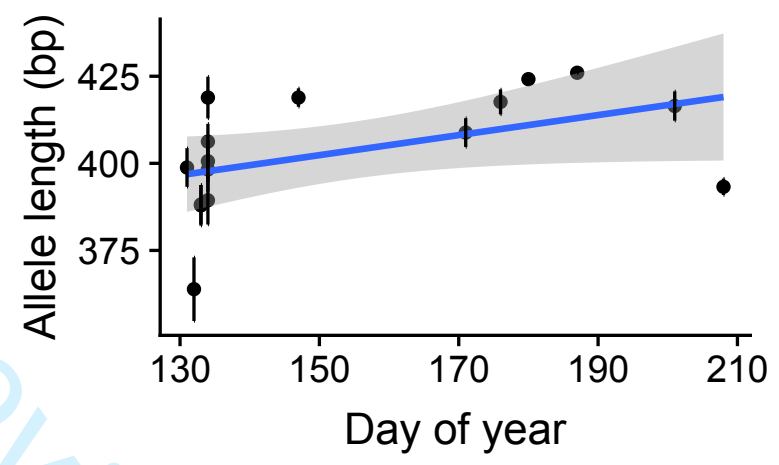

d)

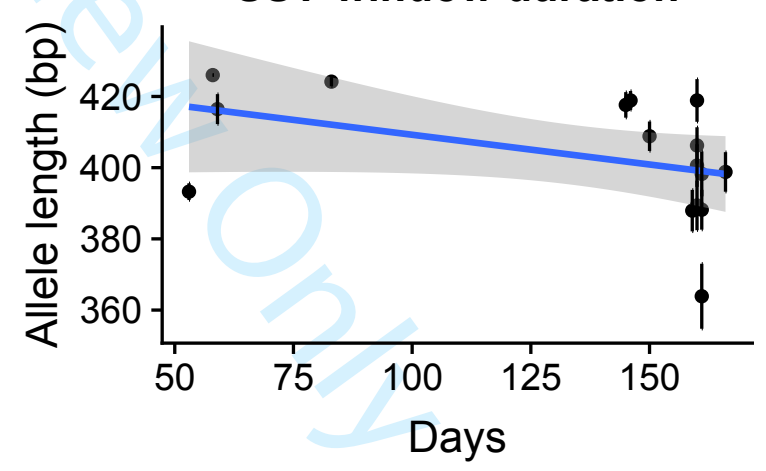

f)

SST-window duration W. Greenland

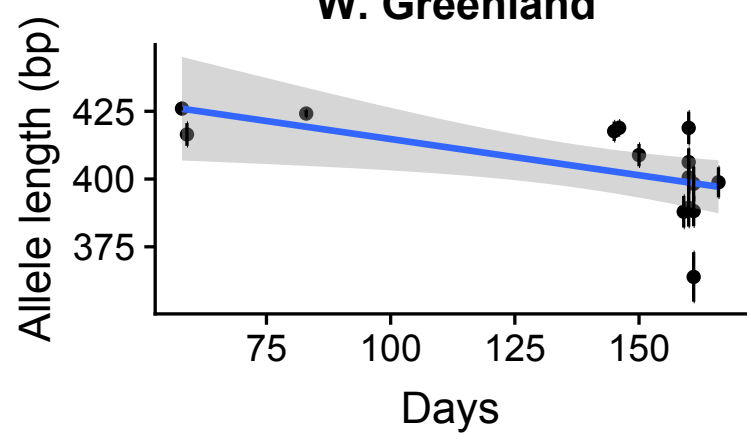




\section{Table S2 Summary statistics}

Summary of analyzed loci along with the total number of alleles obser

* Significance level $p<0.001$ when adjusted for False Discovery Rate

\section{Locus}

Cryptochrome2b.2

Cryptochrome3

Ots515NWFSC

OtsClock1b

Cath2_KC590659

Contig 11261

Contig214_63

Contig2980_70

Contig6336_73

Contig7751_81

Contig92_84

Contig11263_71

Contig 12050

Contig1776_87

Contig2194_67

Contig9220

Contig11431_72

Contig1821_63

Contig2997

Contig4510_74

Contig6593

Contig8674_69

Contig9346_76

Contig11566

Contig12176_62

Contig3057_86

Contig5808_61

Contig7991

Contig8752

Contig3343

Contig12281

Contig11742_67

Contig9421

Contig8976_82

Contig711_65

Contig481

Contig3493_74

Contig2680_72

Contig 1973

Contig1373

\section{Reference}

O'Malley et al (2010b)

O'Malley et al (2010b)

Naish \& Park 2002

O'Malley et al (2007)

Jacobsen et al (2017)

Jacobsen et al (2017)

Jacobsen et al (2017)

Jacobsen et al (2017)

Jacobsen et al (2017)

Jacobsen et al (2017)

Jacobsen et al (2017)

Jacobsen et al (2017)

Jacobsen et al (2017)

Jacobsen et al (2017)

Jacobsen et al (2017)

Jacobsen et al (2017)

Jacobsen et al (2017)

Jacobsen et al (2017)

Jacobsen et al (2017)

Jacobsen et al (2017)

Jacobsen et al (2017)

Jacobsen et al (2017)

Jacobsen et al (2017)

Jacobsen et al (2017)

Jacobsen et al (2017)

Jacobsen et al (2017)

Jacobsen et al (2017)

Jacobsen et al (2017)

Jacobsen et al (2017)

Jacobsen et al (2017)

Jacobsen et al (2017)

Jacobsen et al (2017)

Jacobsen et al (2017)

Jacobsen et al (2017)

Jacobsen et al (2017)

Jacobsen et al (2017)

Jacobsen et al (2017)

Jacobsen et al (2017)

Jacobsen et al (2017)

Jacobsen et al (2017)
Type

Phenology-related locus

Phenology-related locus

Phenology-related locus

Phenology-related locus

SNP

SNP

SNP

SNP

SNP

SNP

SNP

SNP

SNP

SNP

SNP

SNP

SNP

SNP

SNP

SNP

SNP

SNP

SNP

SNP

SNP

SNP

SNP

SNP

SNP

SNP

SNP

SNP

SNP

SNP

SNP

SNP

SNP

SNP

SNP

SNP 
Contig10740_78

Contig959_76

Contig8978_60

Contig7133_66

Contig5917_74

Contig4954

Contig3498

Contig2705

Contig1525_59

Contig11854_70

Contig 10812

Contig9609

Contig609_67

Contig3603_79

Contig2925

Contig 1570

Contig850
Jacobsen et al (2017)

Jacobsen et al (2017)

Jacobsen et al (2017)

Jacobsen et al (2017)

Jacobsen et al (2017)

Jacobsen et al (2017)

Jacobsen et al (2017)

Jacobsen et al (2017)

Jacobsen et al (2017)

Jacobsen et al (2017)

Jacobsen et al (2017)

Jacobsen et al (2017)

Jacobsen et al (2017)

Jacobsen et al (2017)

Jacobsen et al (2017)

Jacobsen et al (2017)

Jacobsen et al (2017)
SNP

SNP

SNP

SNP

SNP

SNP

SNP

SNP

SNP

SNP

SNP

SNP

SNP

SNP

SNP

SNP

SNP 
ved across all populations. For each population observed (Ho) and expected hete

$$
\begin{gathered}
\text { QAAN-1 } \\
\mathrm{N}=18
\end{gathered}
$$

\section{Total number of alleles}

7

4

24

4

2

2

2

2

2

2

2

2

2

2

2

2

2

2

2

2

2

2

2

2

2

2

2

2

2

2

2

2

2

2

2

2

2

2

2

2

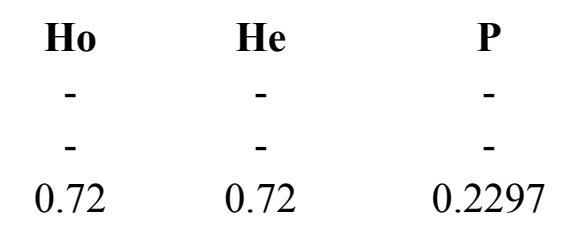

$\begin{array}{lll}0.33 & 0.51 & 0.1447\end{array}$

$\begin{array}{lll}0.22 & 0.20 & 1.000\end{array}$

$\begin{array}{lll}0.17 & 0.16 & 1.000\end{array}$

$\begin{array}{lll}0.33 & 0.29 & 1.000\end{array}$

$\begin{array}{lll}0.28 & 0.25 & 1.0000\end{array}$

- $\quad$ - -

$\begin{array}{lll}- & - \\ - & -\end{array}$

$\begin{array}{ccc}- & - & - \\ 0.89 & 0.51 & 0.000 *\end{array}$

$\begin{array}{lll}0.17 & 0.25 & 0.2903\end{array}$

- $\quad$ -

$\begin{array}{lll}0.33 & 0.41 & 0.5464\end{array}$

$\begin{array}{lll}0.50 & 0.44 & 1\end{array}$

$\begin{array}{lll}0.06 & 0.06 & 1\end{array}$

$0.11 \quad 0.11 \quad 1$

- $\quad$ -

$\begin{array}{lll}0.0 & 0.11 & 0.0225\end{array}$

$0.6 \quad 0.51 \quad 1$

$\begin{array}{lll}0.33 & 0.51 \quad 0.1525\end{array}$

- $\quad$ - $\quad$ -

$\begin{array}{lll}0.39 & 0.32 & 1.0000\end{array}$

- $\quad-\quad-$

$\begin{array}{lll}0.06 & 0.06 & 1.0000\end{array}$

Ecology of Freshwater Fish 


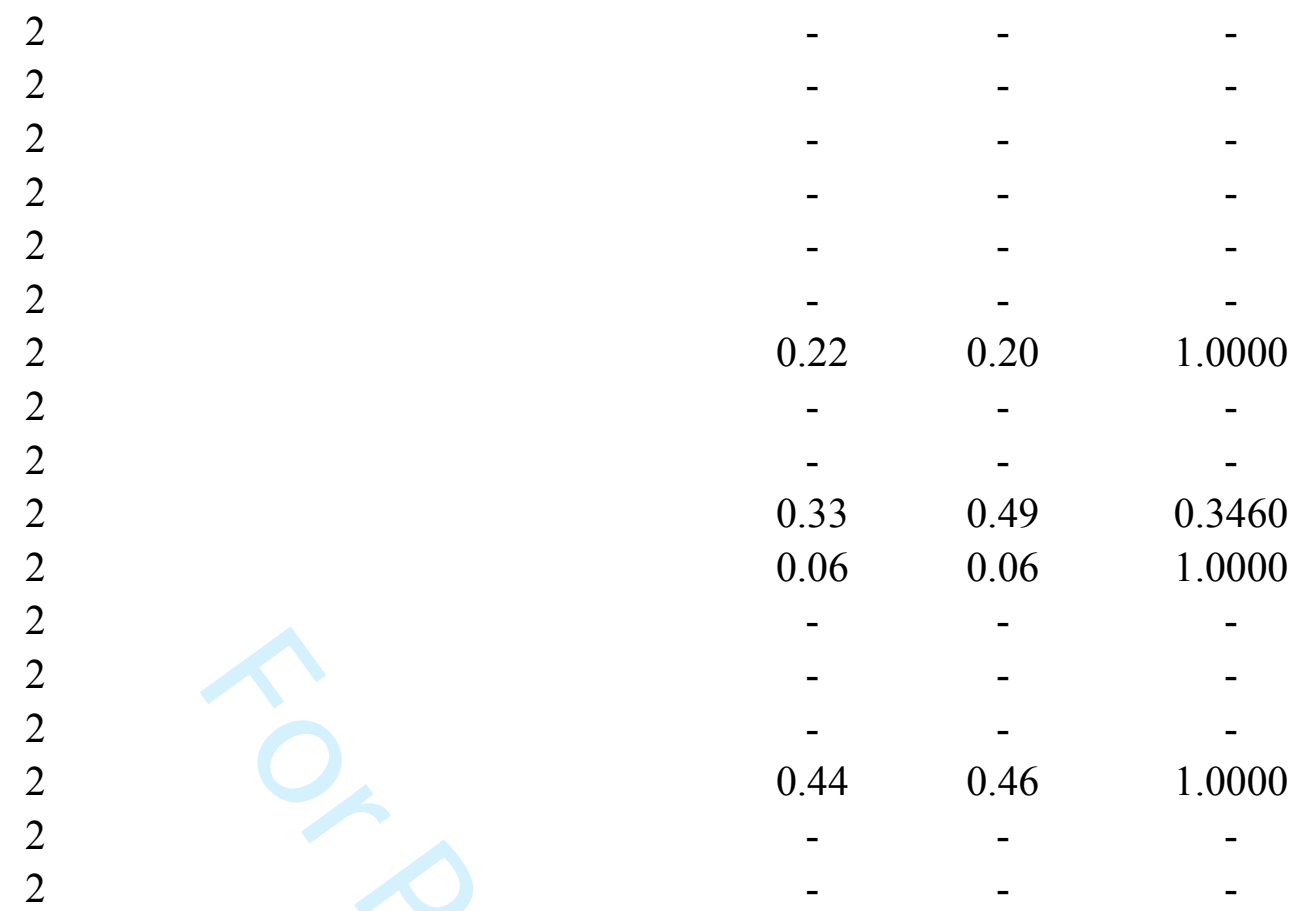


srozygosity $(\mathrm{He})$ is listed along with $\mathrm{P}$-values of tests for conformance to Hardy- $\mathrm{W}$

\section{UUMM-1}

$\mathrm{N}=20$

\section{UUMM-2}

$\mathrm{N}=20$

\begin{tabular}{|c|c|c|c|c|c|}
\hline Но & He & $\mathbf{P}$ & Но & He & $\mathbf{P}$ \\
\hline 0.50 & 0.38 & 0.282 & 0.20 & 0.19 & 1.000 \\
\hline 0.20 & 0.18 & 1.000 & 0.10 & 0.10 & 1.000 \\
\hline 0.60 & 0.74 & 0.056 & 0.50 & 0.73 & 0.000 \\
\hline 0.11 & 0.10 & 1.000 & 0.26 & 0.25 & 1.000 \\
\hline 0.60 & 0.51 & 0.663 & 0.40 & 0.43 & 1.000 \\
\hline 0.40 & 0.47 & 0.655 & 0.25 & 0.30 & 0.469 \\
\hline 0.61 & 0.47 & 0.285 & 0.10 & 0.18 & 0.116 \\
\hline 0.10 & 0.10 & 1.000 & 0.05 & 0.05 & 1.000 \\
\hline 0.10 & 0.10 & 1.000 & 0.45 & 0.41 & 1.000 \\
\hline 0.58 & 0.49 & 0.632 & 0.40 & 0.38 & 1.000 \\
\hline 0.55 & 0.48 & 0.648 & 0.45 & 0.48 & 1.000 \\
\hline 0.45 & 0.45 & 1.000 & 0.35 & 0.48 & 0.337 \\
\hline 0.55 & 0.41 & 0.245 & 0.35 & 0.45 & 0.344 \\
\hline 0.35 & 0.41 & 0.594 & 0.50 & 0.43 & 0.602 \\
\hline 0.40 & 0.38 & 1.000 & 0.45 & 0.51 & 0.674 \\
\hline 0.10 & 0.10 & 1.000 & 0.50 & 0.47 & 1.000 \\
\hline- & - & - & - & - & - \\
\hline 0.25 & 0.22 & 1.000 & 0.35 & 0.30 & 1.000 \\
\hline 0.40 & 0.38 & 1.000 & 0.90 & 0.51 & 0.002 \\
\hline 0.15 & 0.14 & 1.000 & 0.20 & 0.18 & 1.000 \\
\hline 0.35 & 0.50 & 0.178 & 0.30 & 0.33 & 1.000 \\
\hline 0.45 & 0.36 & 0.505 & 0.15 & 0.22 & 0.235 \\
\hline 0.45 & 0.41 & 1.000 & 0.60 & 0.47 & 0.321 \\
\hline 0.30 & 0.33 & 1.000 & 0.60 & 0.51 & 0.661 \\
\hline 0.42 & 0.40 & 1.000 & 0.60 & 0.51 & 0.651 \\
\hline 0.47 & 0.51 & 1.000 & 0.55 & 0.50 & 1.000 \\
\hline- & - & - & - & - & - \\
\hline 0.20 & 0.18 & 1.000 & 0.15 & 0.22 & 0.247 \\
\hline 0.40 & 0.43 & 1.000 & 0.35 & 0.36 & 1.000 \\
\hline 0.15 & 0.14 & 1.000 & 0.40 & 0.43 & 1.000 \\
\hline 0.50 & 0.38 & 0.319 & 0.30 & 0.26 & 1.000 \\
\hline 0.42 & 0.51 & 0.665 & 0.20 & 0.26 & 0.342 \\
\hline 0.58 & 0.51 & 0.679 & 0.00 & 0.10 & 0.025 \\
\hline- & - & - & 0.05 & 0.05 & 1.000 \\
\hline 0.37 & 0.37 & 1.000 & 0.05 & 0.05 & 1.000 \\
\hline 0.05 & 0.05 & 1.000 & 0.05 & 0.05 & 1.000 \\
\hline 0.05 & 0.05 & 1.000 & - & - & - \\
\hline 0.35 & 0.30 & 1.000 & - & - & - \\
\hline 0.30 & 0.26 & 1.000 & 0.45 & 0.41 & 1.000 \\
\hline 0.35 & 0.30 & 1.000 & 0.25 & 0.50 & 0.018 \\
\hline
\end{tabular}




$\begin{array}{cccccc}0.05 & 0.14 & 0.071 & 0.25 & 0.30 & 0.465 \\ 0.15 & 0.14 & 1.000 & - & - & - \\ 0.42 & 0.40 & 1.000 & 0.05 & 0.05 & 1.000 \\ - & - & - & - & - & - \\ - & - & - & - & - & - \\ - & - & - & - & - & - \\ 0.20 & 0.18 & 1.000 & 0.05 & 0.14 & 0.062 \\ 0.35 & 0.45 & 0.332 & 0.53 & 0.40 & 0.234 \\ 0.45 & 0.41 & 1.000 & 0.60 & 0.51 & 0.645 \\ 0.65 & 0.50 & 0.384 & 0.05 & 0.05 & 1.000 \\ 0.20 & 0.18 & 1.000 & - & - & - \\ - & - & - & 0.15 & 0.14 & 1.000 \\ 0.42 & 0.40 & 1.000 & 0.25 & 0.22 & 1.000 \\ - & - & - & - & - & - \\ 0.40 & 0.33 & 0.538 & 0.45 & 0.41 & 1.000 \\ 0.25 & 0.22 & 1.000 & 0.35 & 0.36 & 1.000 \\ 0.15 & 0.14 & 1.000 & 0.55 & 0.45 & 0.577\end{array}$


Veinberg Equilibrium. "-" denotes that the locus was monomorphic within the specif

DISK-1

$\mathrm{N}=20$
KANG-1

$\mathrm{N}=20$

\begin{tabular}{|c|c|c|c|c|c|}
\hline Но & He & $\mathbf{P}$ & Ho & He & $\mathbf{P}$ \\
\hline 0.45 & 0.36 & 0.536 & 0.45 & 0.53 & 0.563 \\
\hline 0.15 & 0.22 & 0.234 & 0.45 & 0.53 & 0.612 \\
\hline 0.75 & 0.84 & $0.000^{*}$ & 0.85 & 0.83 & 0.472 \\
\hline 0.25 & 0.30 & 0.601 & 0.60 & 0.52 & 0.113 \\
\hline 0.15 & 0.14 & 1.000 & - & - & - \\
\hline 0.45 & 0.48 & 1.000 & 0.06 & 0.16 & 0.066 \\
\hline 0.65 & 0.50 & 0.361 & 0.30 & 0.43 & 0.271 \\
\hline 0.05 & 0.05 & 1.000 & 0.05 & 0.05 & 1.000 \\
\hline 0.15 & 0.14 & 1.000 & 0.40 & 0.43 & 1.000 \\
\hline 0.65 & 0.50 & 0.331 & 0.20 & 0.43 & 0.034 \\
\hline 0.20 & 0.26 & 0.345 & 0.35 & 0.45 & 0.339 \\
\hline 0.40 & 0.49 & 0.637 & 0.60 & 0.47 & 0.355 \\
\hline 0.45 & 0.45 & 1.000 & 0.45 & 0.45 & 1.000 \\
\hline 0.20 & 0.33 & 0.137 & - & - & - \\
\hline 0.30 & 0.47 & 0.138 & 0.40 & 0.51 & 0.363 \\
\hline 0.25 & 0.22 & 1.000 & 0.55 & 0.50 & 1.000 \\
\hline- & - & - & - & - & - \\
\hline 0.40 & 0.38 & 1.000 & - & - & - \\
\hline 0.75 & 0.48 & 0.010 & 0.40 & 0.51 & 0.432 \\
\hline 0.10 & 0.10 & 1.000 & 0.45 & 0.41 & 1.000 \\
\hline 0.25 & 0.50 & 0.031 & 0.40 & 0.51 & 0.464 \\
\hline 0.30 & 0.51 & 0.081 & 0.20 & 0.18 & 1.000 \\
\hline 0.20 & 0.26 & 0.398 & 0.05 & 0.05 & 1.000 \\
\hline 0.35 & 0.30 & 1.000 & 0.05 & 0.05 & 1.000 \\
\hline 0.25 & 0.41 & 0.099 & 0.10 & 0.10 & 1.000 \\
\hline 0.45 & 0.50 & 0.684 & 0.15 & 0.14 & 1.000 \\
\hline- & - & - & 0.10 & 0.10 & 1.000 \\
\hline 0.40 & 0.43 & 1.000 & 0.30 & 0.26 & 1.000 \\
\hline 0.40 & 0.51 & 0.369 & 0.50 & 0.51 & 1.000 \\
\hline- & - & - & 0.10 & 0.10 & 1.000 \\
\hline- & - & - & 0.05 & 0.05 & 1.000 \\
\hline 0.60 & 0.51 & 0.660 & - & - & - \\
\hline 0.40 & 0.51 & 0.398 & 0.65 & 0.48 & 0.168 \\
\hline- & - & - & 0.10 & 0.10 & 1.000 \\
\hline 0.40 & 0.38 & 1.000 & 0.10 & 0.10 & 1.000 \\
\hline 0.05 & 0.14 & 0.096 & - & - & - \\
\hline 0.25 & 0.22 & 1.000 & 0.15 & 0.22 & 0.231 \\
\hline 0.05 & 0.05 & 1.000 & 0.15 & 0.14 & 1.000 \\
\hline 0.40 & 0.47 & 0.618 & 0.55 & 0.45 & 0.633 \\
\hline 0.55 & 0.45 & 0.613 & 0.10 & 0.10 & 1.000 \\
\hline
\end{tabular}




$\begin{array}{cccccc}0.55 & 0.50 & 1.000 & 0.55 & 0.51 & 1.000 \\ 0.20 & 0.18 & 1.000 & 0.10 & 0.10 & 1.000 \\ 0.35 & 0.30 & 1.000 & - & - & - \\ - & - & - & - & - & - \\ - & - & - & - & - & - \\ - & - & - & - & - & - \\ 0.15 & 0.14 & 1.000 & 0.15 & 0.14 & 1.000 \\ 0.50 & 0.38 & 0.321 & 0.40 & 0.49 & 0.634 \\ 0.55 & 0.51 & 1.000 & 0.25 & 0.30 & 0.434 \\ 0.35 & 0.36 & 1.000 & 0.40 & 0.49 & 0.674 \\ 0.30 & 0.26 & 1.000 & - & - & - \\ 0.10 & 0.10 & 1.000 & 0.50 & 0.43 & 0.627 \\ 0.30 & 0.38 & 0.545 & 0.55 & 0.50 & 1.000 \\ 0.10 & 0.10 & 1.000 & - & - & - \\ 0.50 & 0.43 & 0.622 & 0.35 & 0.51 & 0.232 \\ 0.20 & 0.26 & 0.374 & - & - & - \\ 0.20 & 0.18 & 1.000 & 0.15 & 0.30 & 0.064\end{array}$


fic population.

SISI-1

$\mathrm{N}=20$
MANI-1

$\mathrm{N}=20$
MANI-2

$\mathrm{N}=20$

\begin{tabular}{|c|c|c|c|c|c|c|}
\hline Но & He & $\mathbf{P}$ & Ho & He & $\mathbf{P}$ & Ho \\
\hline 0.50 & 0.52 & 0.653 & 0.60 & 0.51 & 0.647 & 0.70 \\
\hline 0.25 & 0.22 & 1.000 & 0.33 & 0.48 & 0.158 & 0.60 \\
\hline 0.75 & 0.87 & $0.000 *$ & 0.75 & 0.77 & 0.074 & 0.65 \\
\hline 0.53 & 0.61 & 0.266 & 0.65 & 0.68 & 0.346 & 0.65 \\
\hline 0.35 & 0.36 & 1.000 & 0.30 & 0.43 & 0.304 & 0.70 \\
\hline 0.21 & 0.27 & 0.344 & 0.10 & 0.26 & 0.033 & 0.05 \\
\hline 0.25 & 0.36 & 0.217 & 0.35 & 0.30 & 1.000 & 0.05 \\
\hline 0.15 & 0.30 & 0.061 & - & - & - & 0.05 \\
\hline 0.50 & 0.47 & 1.000 & 0.50 & 0.47 & 1.000 & 0.40 \\
\hline 0.40 & 0.38 & 1.000 & 0.50 & 0.51 & 1.000 & 0.45 \\
\hline 0.45 & 0.36 & 0.531 & 0.10 & 0.10 & 1.000 & 0.20 \\
\hline 0.55 & 0.45 & 0.622 & 0.35 & 0.36 & 1.000 & 0.40 \\
\hline 0.50 & 0.47 & 1.000 & 0.45 & 0.51 & 0.658 & 0.40 \\
\hline 0.37 & 0.31 & 1.000 & - & - & - & - \\
\hline 0.25 & 0.22 & 1.000 & 0.40 & 0.43 & 1.000 & 0.30 \\
\hline 0.35 & 0.48 & 0.327 & 0.40 & 0.43 & 1.000 & 0.50 \\
\hline- & - & - & 0.10 & 0.10 & 1.000 & - \\
\hline- & - & - & 0.15 & 0.14 & 1.000 & 0.10 \\
\hline 0.30 & 0.38 & 0.594 & 0.15 & 0.36 & 0.023 & 0.40 \\
\hline 0.55 & 0.45 & 0.600 & 0.60 & 0.51 & 0.661 & 0.50 \\
\hline 0.55 & 0.45 & 0.633 & 0.30 & 0.43 & 0.269 & 0.45 \\
\hline 0.26 & 0.31 & 0.513 & 0.20 & 0.26 & 0.358 & 0.45 \\
\hline 0.15 & 0.14 & 1.000 & - & - & - & 0.10 \\
\hline 0.25 & 0.36 & 0.196 & 0.35 & 0.30 & 1.000 & 0.30 \\
\hline 0.47 & 0.42 & 1.000 & 0.20 & 0.26 & 0.374 & 0.15 \\
\hline 0.26 & 0.42 & 0.095 & 0.25 & 0.30 & 0.469 & 0.35 \\
\hline 0.26 & 0.23 & 1.000 & 0.30 & 0.38 & 0.553 & - \\
\hline 0.63 & 0.48 & 0.303 & 0.58 & 0.42 & 0.240 & 0.60 \\
\hline 0.32 & 0.27 & 1.000 & 0.65 & 0.51 & 0.326 & 0.55 \\
\hline 0.26 & 0.49 & 0.088 & 0.40 & 0.43 & 1.000 & 0.20 \\
\hline 0.26 & 0.23 & 1.000 & 0.35 & 0.30 & 1.000 & 0.05 \\
\hline 0.21 & 0.19 & 1.000 & 0.05 & 0.05 & 1.000 & 0.10 \\
\hline 0.53 & 0.51 & 1.000 & 0.45 & 0.51 & 0.652 & 0.55 \\
\hline 0.47 & 0.37 & 0.517 & 0.40 & 0.38 & 1.000 & 0.55 \\
\hline 0.47 & 0.37 & 0.508 & 0.50 & 0.49 & 1.000 & 0.20 \\
\hline 0.11 & 0.10 & 1.000 & - & - & - & 0.10 \\
\hline 0.11 & 0.10 & 1.000 & 0.30 & 0.26 & 1.000 & 0.35 \\
\hline 0.21 & 0.19 & 1.000 & 0.10 & 0.10 & 1.000 & 0.20 \\
\hline 0.42 & 0.40 & 1.000 & 0.55 & 0.41 & 0.269 & 0.50 \\
\hline 0.32 & 0.27 & 1.000 & 0.20 & 0.18 & 1.000 & 0.25 \\
\hline
\end{tabular}




$\begin{array}{ccccccc}0.50 & 0.47 & 1.000 & 0.10 & 0.18 & 0.162 & 0.10 \\ 0.32 & 0.27 & 1.000 & 0.50 & 0.47 & 1.000 & 0.25 \\ 0.45 & 0.48 & 1.000 & 0.45 & 0.41 & 1.000 & 0.50 \\ - & - & - & 0.05 & 0.05 & 1.000 & - \\ - & - & - & - & - & - & - \\ 0.05 & 0.05 & 1.000 & 0.40 & 0.33 & 0.565 & - \\ 0.15 & 0.14 & 1.000 & 0.40 & 0.33 & 0.541 & 0.25 \\ 0.60 & 0.49 & 0.370 & 0.35 & 0.48 & 0.367 & 0.35 \\ 0.47 & 0.51 & 1.000 & 0.55 & 0.45 & 0.606 & 0.05 \\ 0.50 & 0.49 & 1.000 & 0.45 & 0.50 & 0.713 & 0.40 \\ 0.30 & 0.26 & 1.000 & 0.25 & 0.30 & 0.484 & - \\ 0.55 & 0.48 & 0.623 & 0.55 & 0.41 & 0.256 & 0.30 \\ 0.70 & 0.49 & 0.087 & 0.50 & 0.49 & 1.000 & 0.30 \\ - & - & - & - & - & - & - \\ 0.35 & 0.41 & 0.573 & 0.45 & 0.48 & 1.000 & - \\ 0.20 & 0.18 & 1.000 & 0.10 & 0.10 & 1.000 & 0.50 \\ 0.05 & 0.05 & 1.000 & 0.45 & 0.36 & 0.534 & 0.25\end{array}$


NUUK-1

NUUK-2

$\mathrm{N}=20$

$\mathrm{N}=20$

\begin{tabular}{|c|c|c|c|c|c|}
\hline $\mathbf{H e}$ & $\mathbf{P}$ & Но & $\mathbf{H e}$ & $\mathbf{P}$ & Ho \\
\hline 0.51 & 0.165 & 0.50 & 0.39 & 0.487 & 0.47 \\
\hline 0.59 & 0.570 & 0.06 & 0.06 & 1.000 & 0.21 \\
\hline 0.71 & 0.157 & 0.67 & 0.75 & 0.196 & 1.00 \\
\hline 0.54 & 0.660 & 0.67 & 0.67 & 0.890 & 0.53 \\
\hline 0.51 & 0.190 & 0.44 & 0.51 & 0.657 & 0.16 \\
\hline 0.14 & 0.070 & 0.22 & 0.29 & 0.394 & 0.05 \\
\hline 0.14 & 0.070 & 0.28 & 0.32 & 0.489 & - \\
\hline 0.05 & 1.000 & - & - & - & 0.21 \\
\hline 0.51 & 0.396 & 0.28 & 0.39 & 0.264 & 0.58 \\
\hline 0.50 & 0.658 & 0.39 & 0.47 & 0.626 & 0.47 \\
\hline 0.33 & 0.139 & 0.22 & 0.29 & 0.447 & 0.16 \\
\hline 0.38 & 1.000 & 0.67 & 0.49 & 0.140 & 0.50 \\
\hline 0.38 & 1.000 & 0.33 & 0.41 & 0.537 & 0.37 \\
\hline- & - & - & - & - & 0.05 \\
\hline 0.33 & 1.000 & 0.44 & 0.46 & 1.000 & 0.47 \\
\hline 0.38 & 0.242 & 0.50 & 0.50 & 1.000 & 0.47 \\
\hline- & - & - & - & - & 0.11 \\
\hline 0.10 & 1.000 & - & - & - & 0.11 \\
\hline 0.38 & 1.000 & 0.39 & 0.39 & 1.000 & 0.42 \\
\hline 0.38 & 0.277 & 0.56 & 0.51 & 1.000 & 0.42 \\
\hline 0.48 & 1.000 & 0.33 & 0.29 & 1.000 & 0.37 \\
\hline 0.50 & 0.706 & 0.06 & 0.06 & 1.000 & 0.37 \\
\hline 0.10 & 1.000 & - & - & - & 0.11 \\
\hline 0.26 & 1.000 & 0.11 & 0.11 & 1.000 & 0.16 \\
\hline 0.22 & 0.242 & 0.44 & 0.49 & 1.000 & 0.47 \\
\hline 0.51 & 0.207 & 0.28 & 0.39 & 0.239 & 0.16 \\
\hline- & - & 0.39 & 0.44 & 1.000 & 0.21 \\
\hline 0.51 & 0.658 & 0.22 & 0.20 & 1.000 & 0.63 \\
\hline 0.50 & 1.000 & 0.50 & 0.39 & 0.540 & 0.58 \\
\hline 0.18 & 1.000 & - & - & - & 0.16 \\
\hline 0.05 & 1.000 & 0.28 & 0.25 & 1.000 & 0.32 \\
\hline 0.10 & 1.000 & - & - & - & 0.11 \\
\hline 0.51 & 1.000 & 0.44 & 0.49 & 1.000 & 0.58 \\
\hline 0.48 & 0.625 & 0.06 & 0.06 & 1.000 & 0.42 \\
\hline 0.26 & 0.392 & 0.39 & 0.47 & 0.585 & 0.21 \\
\hline 0.10 & 1.000 & 0.11 & 0.11 & 1.000 & 0.21 \\
\hline 0.48 & 0.355 & 0.11 & 0.11 & 1.000 & 0.16 \\
\hline 0.18 & 1.000 & 0.17 & 0.16 & 1.000 & 0.21 \\
\hline 0.51 & 1.000 & 0.44 & 0.36 & 0.546 & 0.47 \\
\hline 0.30 & 0.444 & 0.44 & 0.46 & 1.000 & 0.16 \\
\hline
\end{tabular}




$\begin{array}{cccccc}0.10 & 1.000 & - & - & - & 0.21 \\ 0.30 & 0.422 & - & - & - & 0.16 \\ 0.49 & 1.000 & 0.11 & 0.11 & 1.000 & 0.58 \\ - & - & - & - & - & - \\ - & - & - & - & - & 0.11 \\ - & - & 0.11 & 0.11 & 1.000 & 0.05 \\ 0.30 & 0.456 & 0.11 & 0.11 & 1.000 & 0.16 \\ 0.30 & 1.000 & 0.11 & 0.11 & 1.000 & 0.37 \\ 0.05 & 1.000 & 0.50 & 0.44 & 1.000 & 0.32 \\ 0.49 & 0.644 & 0.28 & 0.32 & 0.478 & 0.26 \\ - & - & - & - & - & 0.16 \\ 0.47 & 0.127 & 0.06 & 0.16 & 0.087 & 0.42 \\ 0.47 & 0.131 & 0.17 & 0.39 & 0.014 & 0.53 \\ - & - & - & - & - & 0.05 \\ - & - & 0.28 & 0.32 & 0.513 & 0.26 \\ 0.43 & 0.618 & 0.28 & 0.32 & 0.515 & 0.11 \\ 0.22 & 1.000 & 0.17 & 0.16 & 1.000 & 0.11\end{array}$


NUUK-5

NUUK-3

$\mathrm{N}=20$

$\mathrm{N}=20$

\begin{tabular}{|c|c|c|c|c|c|c|}
\hline He & $\mathbf{P}$ & Но & He & $\mathbf{P}$ & Ho & He \\
\hline 0.37 & 0.521 & 0.41 & 0.62 & 0.015 & 0.65 & 0.51 \\
\hline 0.20 & 1.000 & 0.26 & 0.28 & 0.291 & 0.20 & 0.19 \\
\hline 0.93 & 1.000 & 0.80 & 0.79 & 0.338 & 0.90 & 0.88 \\
\hline 0.53 & 0.879 & 0.60 & 0.53 & 0.091 & 0.30 & 0.30 \\
\hline 0.46 & 0.002 & 0.45 & 0.48 & 1.000 & 0.50 & 0.51 \\
\hline 0.05 & 1.000 & - & - & - & - & - \\
\hline- & - & 0.30 & 0.26 & 1.000 & - & - \\
\hline 0.19 & 1.000 & 0.25 & 0.22 & 1.000 & - & - \\
\hline 0.46 & 0.356 & 0.55 & 0.51 & 1.000 & 0.60 & 0.52 \\
\hline 0.51 & 1.000 & 0.45 & 0.48 & 1.000 & 0.58 & 0.51 \\
\hline 0.23 & 0.263 & 0.10 & 0.10 & 1.000 & 0.25 & 0.22 \\
\hline 0.39 & 0.523 & 0.30 & 0.33 & 1.000 & 0.20 & 0.38 \\
\hline 0.37 & 1.000 & 0.25 & 0.41 & 0.089 & 0.30 & 0.47 \\
\hline 0.05 & 1.000 & 0.05 & 0.05 & 1.000 & 0.10 & 0.10 \\
\hline 0.51 & 1.000 & 0.35 & 0.41 & 0.564 & 0.25 & 0.48 \\
\hline 0.49 & 1.000 & 0.25 & 0.36 & 0.233 & 0.30 & 0.51 \\
\hline 0.10 & 1.000 & - & - & - & - & - \\
\hline 0.10 & 1.000 & 0.20 & 0.18 & 1.000 & 0.10 & 0.18 \\
\hline 0.40 & 1.000 & 0.25 & 0.41 & 0.103 & 0.37 & 0.42 \\
\hline 0.40 & 1.000 & 0.50 & 0.51 & 1.000 & 0.40 & 0.43 \\
\hline 0.49 & 0.362 & 0.40 & 0.47 & 0.652 & 0.50 & 0.47 \\
\hline 0.42 & 0.572 & 0.40 & 0.49 & 0.655 & 0.30 & 0.47 \\
\hline 0.10 & 1.000 & 0.10 & 0.10 & 1.000 & 0.20 & 0.18 \\
\hline 0.23 & 0.292 & 0.35 & 0.41 & 0.595 & 0.32 & 0.40 \\
\hline 0.42 & 1.000 & 0.50 & 0.43 & 0.630 & 0.50 & 0.49 \\
\hline 0.15 & 1.000 & 0.15 & 0.14 & 1.000 & 0.30 & 0.33 \\
\hline 0.27 & 0.368 & 0.40 & 0.38 & 1.000 & 0.25 & 0.22 \\
\hline 0.50 & 0.346 & 0.50 & 0.51 & 1.000 & 0.35 & 0.30 \\
\hline 0.51 & 0.645 & 0.45 & 0.51 & 0.690 & 0.45 & 0.48 \\
\hline 0.15 & 1.000 & 0.30 & 0.26 & 1.000 & 0.30 & 0.26 \\
\hline 0.40 & 0.555 & 0.15 & 0.14 & 1.000 & 0.20 & 0.26 \\
\hline 0.10 & 1.000 & 0.20 & 0.18 & 1.000 & 0.10 & 0.10 \\
\hline 0.51 & 0.617 & 0.25 & 0.45 & 0.114 & 0.55 & 0.48 \\
\hline 0.40 & 1.000 & 0.25 & 0.22 & 1.000 & 0.20 & 0.18 \\
\hline 0.34 & 0.127 & 0.40 & 0.47 & 0.597 & 0.45 & 0.50 \\
\hline 0.27 & 0.353 & 0.15 & 0.22 & 0.219 & 0.25 & 0.22 \\
\hline 0.15 & 1.000 & 0.05 & 0.14 & 0.083 & 0.10 & 0.10 \\
\hline 0.19 & 1.000 & 0.15 & 0.14 & 1.000 & 0.20 & 0.18 \\
\hline 0.51 & 1.000 & 0.40 & 0.51 & 0.392 & 0.40 & 0.47 \\
\hline 0.15 & 1.000 & 0.40 & 0.43 & 1.000 & 0.20 & 0.18 \\
\hline
\end{tabular}




$\begin{array}{ccccccc}0.19 & 1.000 & 0.30 & 0.33 & 1.000 & 0.10 & 0.10 \\ 0.15 & 1.000 & 0.10 & 0.18 & 0.201 & 0.15 & 0.30 \\ 0.46 & 0.386 & 0.40 & 0.38 & 1.000 & 0.25 & 0.36 \\ - & - & - & - & - & - & - \\ 0.10 & 1.000 & - & - & - & - & - \\ 0.15 & 0.096 & 0.15 & 0.14 & 1.000 & 0.10 & 0.10 \\ 0.15 & 1.000 & 0.25 & 0.22 & 1.000 & 0.15 & 0.14 \\ 0.51 & 0.351 & 0.35 & 0.48 & 0.351 & 0.35 & 0.41 \\ 0.27 & 1.000 & 0.25 & 0.22 & 1.000 & 0.15 & 0.14 \\ 0.23 & 1.000 & 0.60 & 0.43 & 0.120 & 0.45 & 0.36 \\ 0.23 & 0.248 & 0.25 & 0.22 & 1.000 & 0.20 & 0.18 \\ 0.34 & 0.531 & 0.40 & 0.33 & 0.524 & 0.25 & 0.22 \\ 0.50 & 1.000 & 0.65 & 0.48 & 0.168 & 0.40 & 0.47 \\ 0.05 & 1.000 & 0.10 & 0.10 & 1.000 & - & - \\ 0.31 & 0.516 & 0.30 & 0.26 & 1.000 & 0.25 & 0.22 \\ 0.19 & 0.170 & 0.15 & 0.22 & 0.262 & 0.20 & 0.26 \\ 0.10 & 1.000 & 0.20 & 0.18 & 1.000 & 0.30 & 0.26\end{array}$


NUUK-4

$\mathrm{N}=20$

\section{QAQO-1}

$\mathrm{N}=20$

\begin{tabular}{|c|c|c|c|c|c|c|}
\hline $\mathbf{P}$ & Но & He & $\mathbf{P}$ & Ho & He & $\mathbf{P}$ \\
\hline 0.35 & 0.26 & 1.00 & $0.000 *$ & 0.10 & 0.18 & 0.159 \\
\hline 1.00 & 0.75 & 0.52 & 0.023 & 0.15 & 0.14 & 1.000 \\
\hline 0.78 & 0.90 & 0.75 & 0.603 & 0.65 & 0.72 & 0.223 \\
\hline 0.19 & 0.58 & 0.57 & 0.408 & 0.45 & 0.53 & 0.335 \\
\hline 1.00 & 0.45 & 0.45 & 1.000 & 0.30 & 0.33 & 1.000 \\
\hline- & 0.15 & 0.14 & 1.000 & - & - & - \\
\hline- & 0.10 & 0.10 & 1.000 & - & - & - \\
\hline- & 0.10 & 0.10 & 1.000 & - & - & - \\
\hline 0.67 & 0.45 & 0.48 & 1.000 & 0.20 & 0.18 & 1.000 \\
\hline 0.66 & 0.35 & 0.30 & 1.000 & 0.45 & 0.48 & 1.000 \\
\hline 1.00 & 0.20 & 0.18 & 1.000 & - & - & - \\
\hline 0.08 & 0.40 & 0.33 & 0.538 & 0.50 & 0.51 & 1.000 \\
\hline 0.17 & 0.35 & 0.36 & 1.000 & 0.20 & 0.38 & 0.083 \\
\hline 1.00 & 0.25 & 0.22 & 1.000 & - & - & - \\
\hline 0.07 & 0.35 & 0.45 & 0.377 & 0.35 & 0.30 & 1.000 \\
\hline 0.08 & 0.45 & 0.45 & 1.000 & 0.30 & 0.33 & 1.000 \\
\hline- & - & - & - & - & - & - \\
\hline 0.17 & 0.30 & 0.33 & 1.000 & - & - & - \\
\hline 0.61 & 0.30 & 0.43 & 0.281 & 0.05 & 0.05 & 1.000 \\
\hline 1.00 & 0.40 & 0.38 & 1.000 & 0.30 & 0.38 & 0.519 \\
\hline 1.00 & 0.25 & 0.22 & 1.000 & 0.05 & 0.05 & 1.000 \\
\hline 0.15 & 0.75 & 0.51 & 0.070 & 0.45 & 0.48 & 1.000 \\
\hline 1.00 & 0.10 & 0.18 & 0.142 & - & - & - \\
\hline 0.54 & 0.45 & 0.45 & 1.000 & - & - & - \\
\hline 1.00 & 0.30 & 0.43 & 0.307 & 0.40 & 0.51 & 0.413 \\
\hline 1.00 & 0.30 & 0.33 & 1.000 & & - & - \\
\hline 1.00 & 0.15 & 0.14 & 1.000 & 0.55 & 0.50 & 1.000 \\
\hline 1.00 & 0.45 & 0.48 & 1.000 & 0.15 & 0.14 & 1.000 \\
\hline 1.00 & 0.60 & 0.51 & 0.653 & 0.25 & 0.22 & 1.000 \\
\hline 1.00 & 0.10 & 0.10 & 1.000 & - & - & - \\
\hline 0.36 & 0.25 & 0.50 & 0.043 & - & - & - \\
\hline 1.00 & 0.10 & 0.10 & 1.000 & - & - & - \\
\hline 0.62 & 0.65 & 0.50 & 0.346 & 0.10 & 0.10 & 1.000 \\
\hline 1.00 & 0.20 & 0.18 & 1.000 & 0.05 & 0.05 & 1.000 \\
\hline 0.66 & 0.55 & 0.48 & 0.631 & 0.35 & 0.51 & 0.210 \\
\hline 1.00 & - & - & - & 0.25 & 0.22 & 1.000 \\
\hline 1.00 & 0.05 & 0.05 & 1.000 & 0.15 & 0.14 & 1.000 \\
\hline 1.00 & 0.15 & 0.14 & 1.000 & 0.30 & 0.38 & 0.533 \\
\hline 0.63 & 0.35 & 0.36 & 1.000 & 0.21 & 0.19 & 1.000 \\
\hline 1.00 & 0.25 & 0.22 & 1.000 & 0.35 & 0.36 & 1.000 \\
\hline
\end{tabular}




$\begin{array}{cccccccc}1.00 & 0.25 & 0.30 & 0.460 & - & - & - \\ 0.07 & 0.35 & 0.30 & 1.000 & - & - & - \\ 0.23 & 0.40 & 0.33 & 0.565 & 0.55 & 0.48 & 0.691 \\ - & 0.35 & 0.36 & 1.000 & - & - & - \\ - & 0.15 & 0.14 & 1.000 & - & - & - \\ 1.00 & 0.40 & 0.33 & 0.536 & 0.05 & 0.14 & 0.062 \\ 1.00 & 0.25 & 0.36 & 0.250 & - & - & - \\ 0.59 & 0.45 & 0.48 & 1.000 & 0.55 & 0.51 & 1.000 \\ 1.00 & 0.15 & 0.22 & 0.246 & 0.15 & 0.14 & 1.000 \\ 0.53 & 0.45 & 0.41 & 1.000 & 0.30 & 0.38 & 0.527 \\ 1.00 & 0.20 & 0.18 & 1.000 & - & - & - \\ 1.00 & 0.50 & 0.38 & 0.318 & - & - & - \\ 0.62 & 0.40 & 0.51 & 0.395 & 0.05 & 0.05 & 1.000 \\ - & 0.20 & 0.18 & 1.000 & - & - & - \\ 1.00 & 0.25 & 0.30 & 0.467 & - & - & - \\ 0.34 & 0.20 & 0.26 & 0.373 & 0.15 & 0.22 & 0.281 \\ 1.00 & 0.20 & 0.26 & 0.331 & 0.50 & 0.49 & 1.000\end{array}$


QAQO-2

$\mathrm{N}=20$
SCOR-1

$\mathrm{N}=20$

\begin{tabular}{|c|c|c|c|c|c|}
\hline Но & He & $\mathbf{P}$ & Но & He & $\mathbf{P}$ \\
\hline 0.50 & 0.44 & 1.000 & 0.20 & 0.27 & 0.370 \\
\hline 0.05 & 0.05 & 1.000 & - & - & - \\
\hline 0.84 & 0.88 & 0.443 & 0.70 & 0.86 & 0.141 \\
\hline 0.26 & 0.28 & 0.217 & 0.16 & 0.24 & 0.319 \\
\hline 0.35 & 0.30 & 1.000 & 0.40 & 0.43 & 1.000 \\
\hline- & - & - & - & - & - \\
\hline- & & - & - & - & - \\
\hline- & 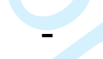 & - & - & - & - \\
\hline 0.40 & 0.33 & 0.529 & - & - & - \\
\hline 0.45 & 0.48 & 1.000 & 0.60 & 0.51 & 0.653 \\
\hline- & - & - & - & - & - \\
\hline 0.45 & 0.50 & 0.678 & 0.10 & 0.10 & 1.000 \\
\hline 0.40 & 0.47 & 0.656 & 0.05 & 0.05 & 1.000 \\
\hline 0.10 & 0.10 & 1.000 & - & - & - \\
\hline 0.10 & 0.10 & 1.000 & - & - & - \\
\hline 0.25 & 0.30 & 0.455 & 0.35 & 0.48 & 0.346 \\
\hline- & - & - & - & - & - \\
\hline- & - & - & - & - & - \\
\hline 0.15 & 0.30 & 0.065 & 0.20 & 0.26 & 0.342 \\
\hline 0.25 & 0.22 & 1.000 & 0.05 & 0.05 & 1.000 \\
\hline- & - & - & - & - & - \\
\hline 0.60 & 0.51 & 0.629 & 0.55 & 0.50 & 1.000 \\
\hline- & - & - & - & - & - \\
\hline- & - & - & - & - & - \\
\hline 0.55 & 0.51 & 1.000 & 0.10 & 0.10 & 1.000 \\
\hline 0.25 & 0.22 & 1.000 & - & - & - \\
\hline 0.10 & 0.18 & 0.105 & - & - & - \\
\hline- & - & - & - & - & - \\
\hline 0.10 & 0.18 & 0.157 & - & - & - \\
\hline- & - & - & - & - & - \\
\hline- & - & - & - & - & - \\
\hline- & - & - & - & - & - \\
\hline 0.25 & 0.30 & 0.513 & 0.60 & 0.51 & 0.690 \\
\hline- & - & - & - & - & - \\
\hline 0.35 & 0.45 & 0.345 & - & - & - \\
\hline- & - & - & 0.15 & 0.14 & 1.000 \\
\hline 0.30 & 0.38 & 0.575 & - & - & - \\
\hline 0.10 & 0.10 & 1.000 & 0.10 & 0.10 & 1.000 \\
\hline 0.30 & 0.38 & 0.546 & 0.25 & 0.51 & 0.021 \\
\hline 0.25 & 0.22 & 1.000 & - & - & - \\
\hline
\end{tabular}




$\begin{array}{cccccc}- & - & - & - & - & - \\ - & - & - & - & - & - \\ 0.30 & 0.26 & 1.000 & - & - & - \\ - & - & - & - & - & - \\ - & - & - & - & - & - \\ - & - & - & 0.25 & 0.22 & 1.000 \\ - & - & - & - & - & - \\ 0.20 & 0.18 & 1.000 & - & - & - \\ 0.15 & 0.14 & 1.000 & - & - & - \\ 0.10 & 0.10 & 1.000 & 0.45 & 0.48 & 1.000 \\ 0.10 & 0.10 & 1.000 & - & - & - \\ 0.05 & 0.05 & 1.000 & - & - & - \\ 0.30 & 0.49 & 0.152 & - & - & - \\ 0.05 & 0.05 & 1.000 & - & - & - \\ 0.05 & 0.14 & 0.078 & - & - & - \\ 0.10 & 0.10 & 1.000 & - & - & - \\ 0.30 & 0.26 & 1.000 & 0.25 & 0.22 & 1.000\end{array}$


ICEL-1

$\mathrm{N}=20$

\section{NORW-1}

$\mathrm{N}=16$

\begin{tabular}{|c|c|c|c|c|c|}
\hline Но & He & $\mathbf{P}$ & Но & He & $\mathbf{P}$ \\
\hline 0.65 & 0.67 & 0.683 & 0.27 & 0.42 & 0.300 \\
\hline 0.30 & 0.26 & 1.000 & 0.06 & 0.06 & 1.000 \\
\hline 0.90 & 0.81 & 0.151 & 0.80 & 0.80 & 0.798 \\
\hline 0.50 & 0.49 & 1.000 & 0.25 & 0.44 & 0.088 \\
\hline 0.25 & 0.36 & 0.211 & 0.13 & 0.39 & 0.014 \\
\hline- & - & - & - & - & - \\
\hline- & - & - & - & - & - \\
\hline- & - & - & - & - & - \\
\hline- & - & - & - & - & - \\
\hline 0.20 & 0.18 & 1.000 & - & - & - \\
\hline- & - & - & - & - & - \\
\hline 0.35 & 0.30 & 1.000 & 0.56 & 0.42 & 0.257 \\
\hline- & - & - & - & - & - \\
\hline- & - & - & - & - & - \\
\hline- & - & - & - & - & - \\
\hline 0.75 & 0.50 & 0.063 & 0.38 & 0.44 & 0.588 \\
\hline- & - & - & - & - & - \\
\hline- & - & - & - & - & - \\
\hline- & - & - & 0.00 & 0.23 & 0.002 \\
\hline 0.10 & 0.10 & 1.000 & - & - & - \\
\hline- & - & - & - & - & - \\
\hline 0.50 & 0.43 & 0.589 & 0.31 & 0.42 & 0.530 \\
\hline- & - & - & - & - & - \\
\hline- & - & - & - & - & - \\
\hline 0.40 & 0.51 & 0.457 & - & - & - \\
\hline- & - & - & - & - & - \\
\hline- & - & - & - & - & - \\
\hline- & - & - & - & - & - \\
\hline- & - & - & - & - & - \\
\hline- & - & - & - & - & - \\
\hline- & - & - & - & - & - \\
\hline- & - & - & - & - & - \\
\hline 0.20 & 0.26 & 0.390 & 0.25 & 0.23 & 1.000 \\
\hline- & - & - & - & - & - \\
\hline 0.20 & 0.18 & 1.000 & 0.06 & 0.18 & 0.067 \\
\hline- & - & - & 0.31 & 0.35 & 1.000 \\
\hline- & - & - & - & - & - \\
\hline- & - & - & - & - & - \\
\hline 0.65 & 0.51 & 0.395 & 0.38 & 0.51 & 0.354 \\
\hline
\end{tabular}




$\begin{array}{cccccc}- & - & - & - & - & - \\ - & - & - & - & - & - \\ - & - & - & - & - & - \\ - & - & - & - & - & - \\ - & - & - & - & - & - \\ 0.05 & 0.05 & 1.000 & - & - & - \\ - & - & - & - & - & - \\ - & - & - & - & - & - \\ - & - & - & - & - & - \\ - & - & - & 0.38 & 0.31 & 1.000 \\ - & - & - & - & - & - \\ - & - & - & - & - & - \\ - & - & - & - & - & - \\ - & - & - & - & - & - \\ - & - & - & - & - & - \\ - & - & - & 0.38 & 0.31 & 1.000 \\ 0.30 & 0.43 & 0.280 & - & - & -\end{array}$

